University of Redlands

\title{
Using GIS to Analyze a Predator-Prey Relationship of the Common Raven and Desert Tortoise
}

A Major Individual Project submitted in partial satisfaction of the requirements

for the degree of Master of Science in Geographic Information Systems

\author{
by \\ Rebecca Lynn Calliss
}

James Ciarrocca, M.S., Chair

Douglas Flewelling, Ph.D.

August 2008 
Using GIS to Analyze a Predator-Prey Relationship of the Common Raven and Desert Tortoise

Copyright @ 2008

by

Rebecca Lynn Calliss 
The report of Rebecca Calliss is approved.

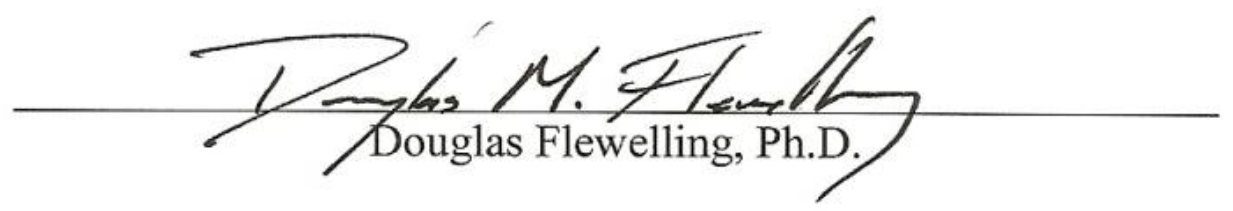

$\frac{\text { Yames Cuavoec a }}{\text { James Ciarrocca, M.S., Chair }}$

August 2008 



\section{ACKNOWLEDGEMENTS}

This journey was an opportunity of a lifetime but it was not easy. I could not have made it without the help and support from my family, my friends, and colleagues.

I would especially like to thank my family (Dennis Calliss, Brenda Calliss, Sarah Work and Lawrence Work) for their support and receiving late night phone calls of worry, stress, and struggles. I would have not made it through this intense program without them. I am very grateful to have them in my life.

I would like to thank Jim Ciarrocca, my advisor, for his help and support through this project.

The friendships I have made with Cohort 12 will last a lifetime and I would like to especially thank them for their help and support. I would like to thank Laura Cathers for her support and retail therapy. I would also like to thank Stephen Benzek for his support and help with SQL queries and other programming problems.

Thanks to Cohort 11 for their help and support as well. I have made friendships that will last a lifetime. 



\begin{abstract}
Using GIS to Analyze a Predator-Prey Relationship of the Common Raven and Desert Tortoise

by

Rebecca Lynn Calliss

The common raven and desert tortoise are species both native to the Mojave Desert in southern California. For the last several decades, however, the raven population has increased significantly, while the desert tortoise population has declined to the point where it has been listed as a threatened species by the U.S. Fish and Wildlife Service under the Endangered Species Act. Prior studies have clearly demonstrated that predation by ravens is one cause of tortoise mortality; however, the correlation between raven population growth, predation locations, and surrounding features within the Mojave Desert (particularly anthropogenic) is less clear. This study focused on collecting and analyzing data on raven predation and habitat using ArcGIS in order to develop better management strategies for controlling raven population growth and increasing survival rates for desert tortoises. This project is a joint effort between the University of Redlands
\end{abstract} and the USFWS. 



\section{Table of Contents}

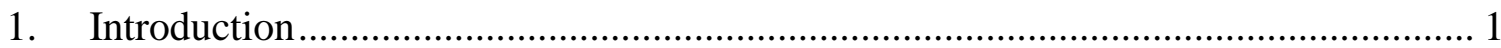

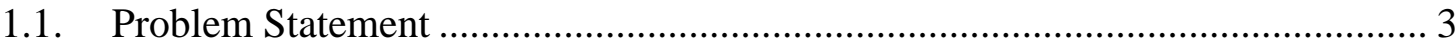

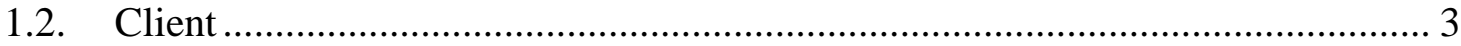

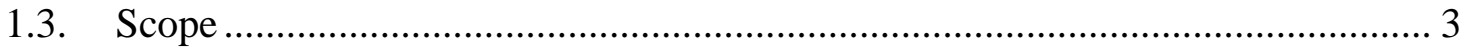

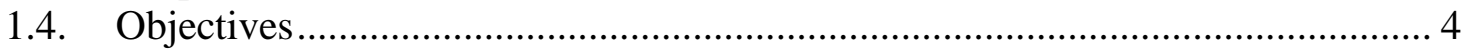

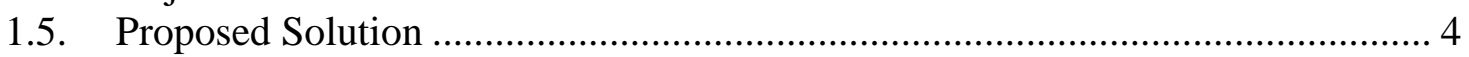

2. Background and Literature Review ……………........................................... 5

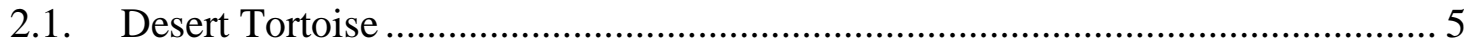

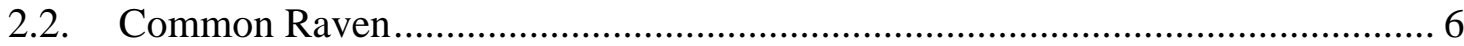

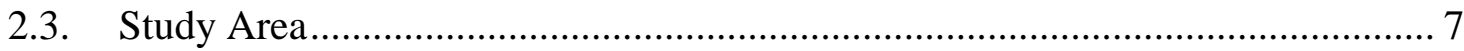

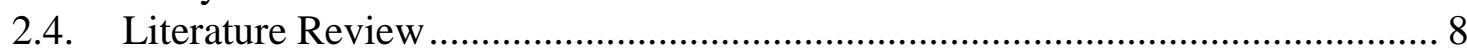

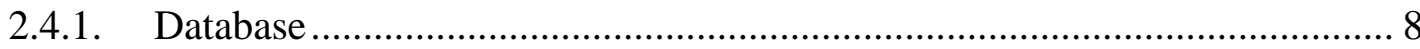

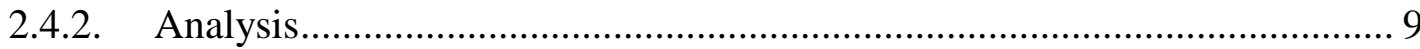

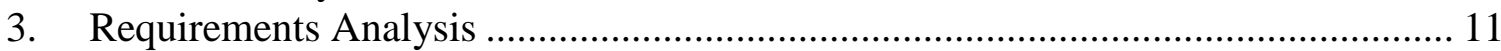

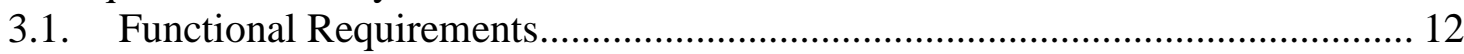

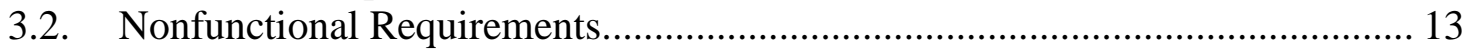

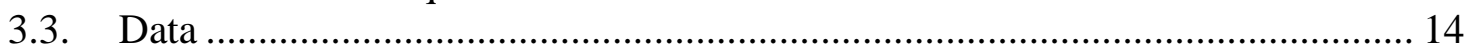

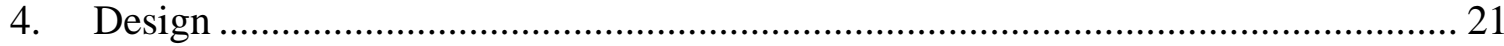

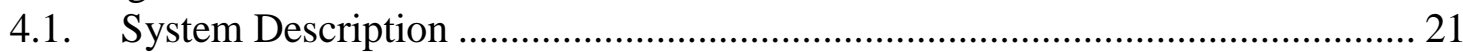

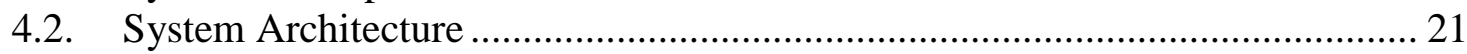

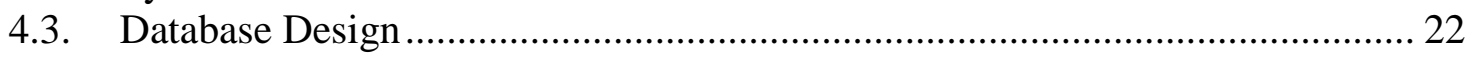

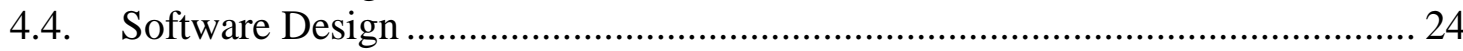

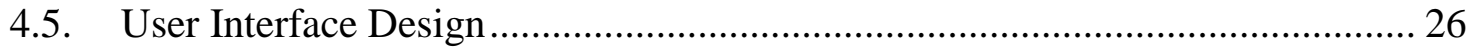

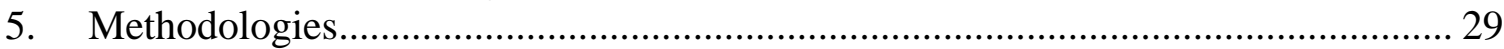

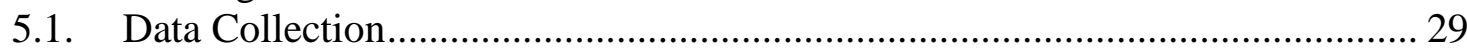

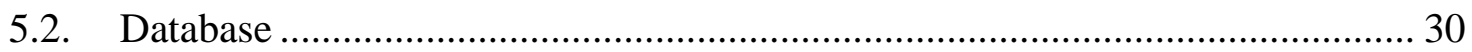

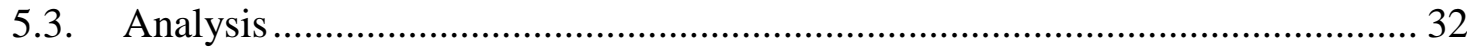

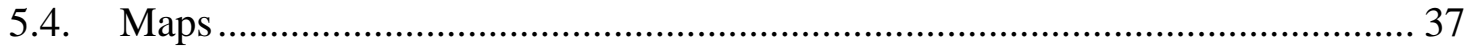

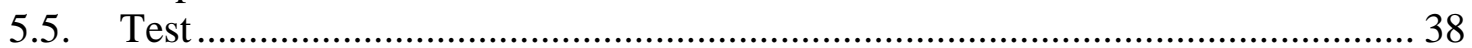

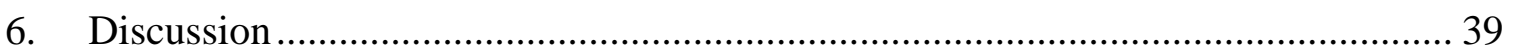

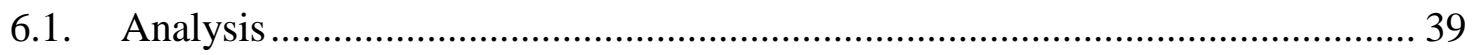

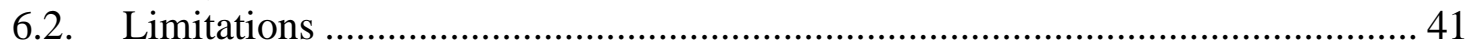

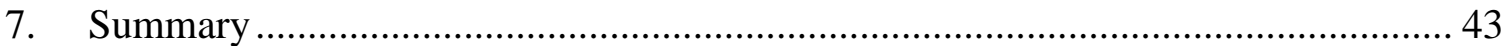

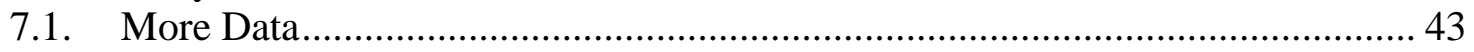

7.2. Design and Custom Interface ………………….......................................... 43

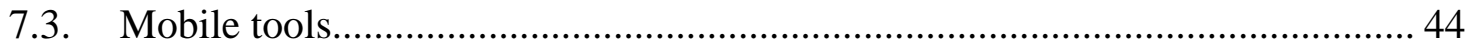

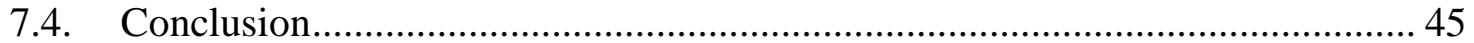

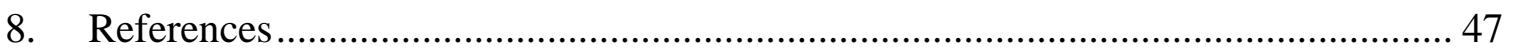

Appendix A-Raven Geodatabase Tutorial .................................................................. 49

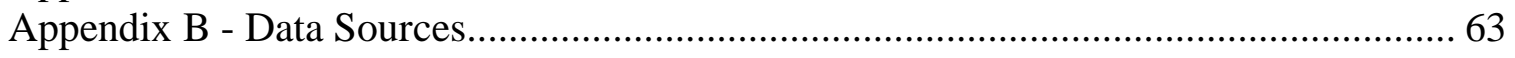





\section{Table of Figures}

Figure 1. Study Area of Observations...................................................................... 2

Figure 2. Study Area with National Parks and Mojave Ecoregion Boundary................... 2

Figure 3. Desert Tortoise (Provided by James Ciarrocca) ............................................ 5

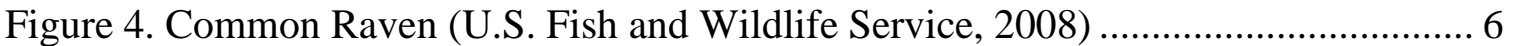

Figure 5. Common Raven Habitat within California....................................................... 7

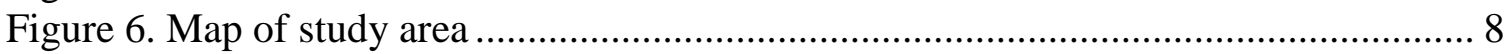

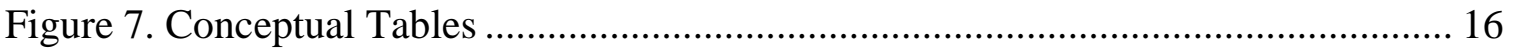

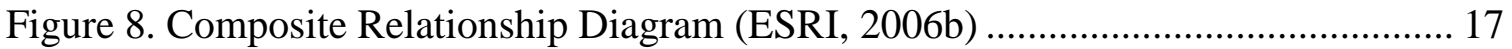

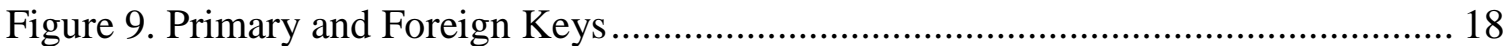

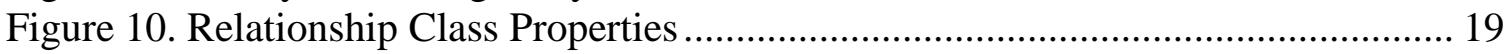

Figure 11. Raven Project System Architecture ....................................................... 22

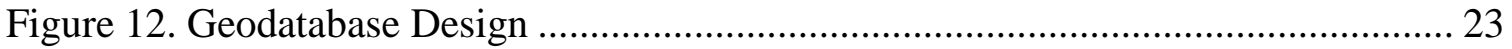

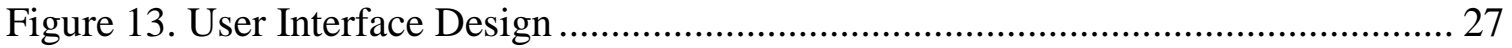

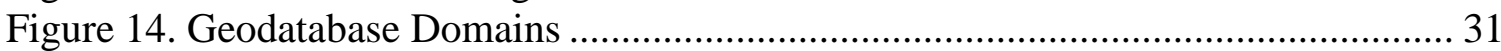

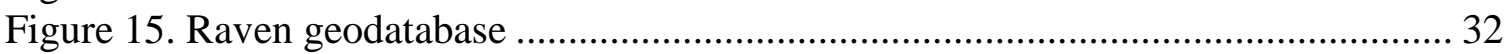

Figure 16. SQL Query........................................................................................ 33

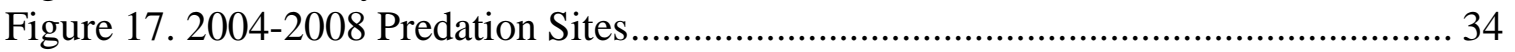

Figure 18. Common Raven Predation from 2004 to 2008 ........................................... 35

Figure 19. Statistics of query selection of Raven Predation under Power Towers for 2004

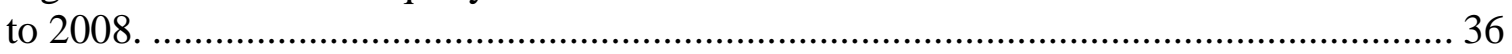

Figure 20. Statistics of Number of Shells for Sites feature Class ................................. 36

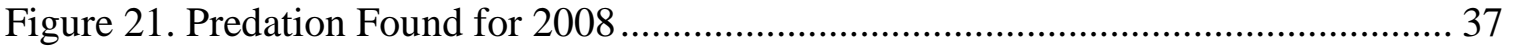

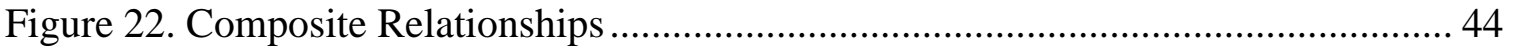





\section{List of Tables}

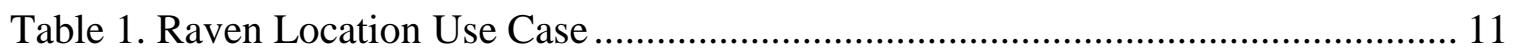

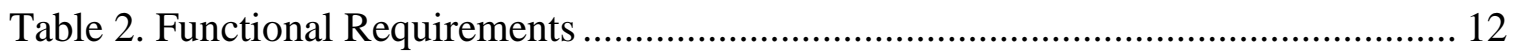

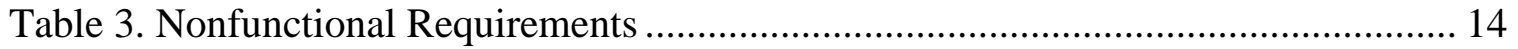

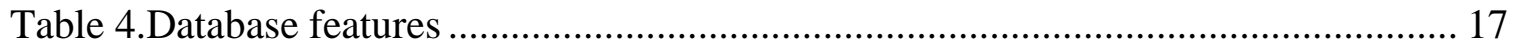

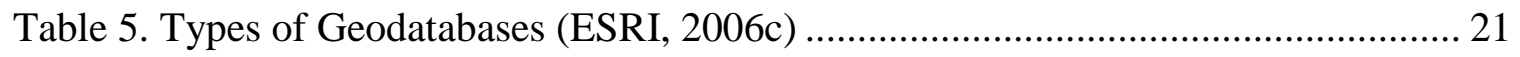

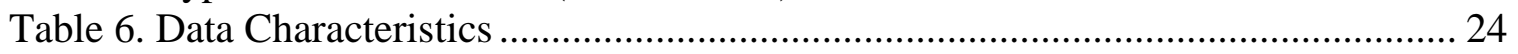

Table 7. Software Use Case Diagram ....................................................................... 25

Table 8. ArcGIS Desktop 9.2 Minimum Requirements (ESRI) ….............................. 25

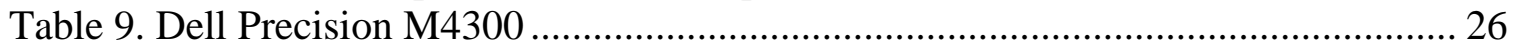

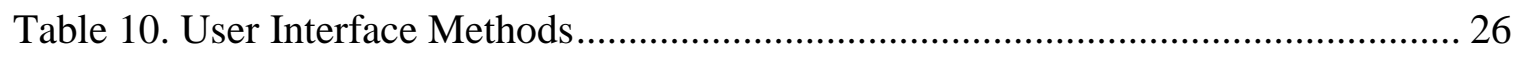

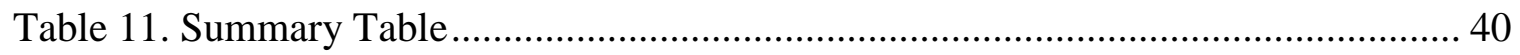





\section{List of Acronyms}

$\begin{array}{ll}\text { DEM } & \begin{array}{l}\text { Digital Elevation Model } \\ \text { Environmental Assessment to Implement a Desert Tortoise Recovery Plan } \\ \text { Task: Reduce the Common Raven Predation on the Desert Tortoise }\end{array} \\ \text { EROS } & \text { Center for Earth Resource Observation Science } \\ \text { ESRI } & \text { Environmental Systems Research Institute } \\ \text { FGDC } & \text { Federal Geographic Data Committee } \\ \text { GIS } & \text { Geographic Information System } \\ \text { MS GIS } & \text { Master of Science Geographic Information Systems } \\ \text { NASA } & \text { National Aeronautics and Space Administration } \\ \text { NGA } & \text { National Geospatial-Intelligence Agency } \\ \text { USFWS } & \text { United States Fish and Wildlife Service } \\ \text { USGS } & \text { United States Geological Survey } \\ \text { UTM } & \text { Universal Transverse Mercator }\end{array}$





\section{Introduction}

The common raven (Corvus corax) and desert tortoise (Gopoherus agassizii) are both native species of the Mojave Desert in southern California. In their natural habitat, these two species will generally maintain a healthy population balance; however, for the past several decades, the common raven population has expanded significantly due to human interaction while the desert tortoise population has declined dramatically (Boarman, 1993, 1997, 2003; Kristan \& Boarman, 2003). This decline in population has been so severe that, in 1990, the desert tortoise was listed as a threatened species by the United States Fish and Wildlife Service (USFWS) under the Endangered Species Act. The common raven preys on the desert tortoise which is one cause of mortality for the desert tortoise (Boarman, 1993, 1997, 2001, 2003; Kristan \& Boarman, 2003).

For the past five years, fieldwork had been performed by Dr. Wendy McIntyre from the Environmental Studies Department at the University of Redlands, in cooperation with the USFWS, to identify areas of heavy raven nesting and predation activity (herein referred to as "hot spots") within the Mojave Desert region of southern California (Figure 1 and Figure 2). This study quantified the number of raven nests and desert tortoise shells found along highways, power lines, Joshua trees, and cliffs (B.M. McIntyre, personal communication, September 26, 2007). The fieldwork, however, had not been used to determine if there was a correlation between the locations of raven predation and surrounding anthropogenic features. Researchers from both the University and the USFWS are anxious to find patterns in the data in order to acquire a better understanding of the raven population. If there is correlation between various features, then management methods could be applied based on these results that might decrease the rapid growth of the common raven. Reducing the raven population is crucial to protecting the desert tortoise population because raven predation has been linked as a contributing factor to their decline (Boarman, 1993, 1997, 2003; Kristan \& Boarman, 2003). As Mukerjee (1930) so pointedly observed so many years ago, "A change in any one fact of the environment brings about a complete change in the milieu, and man is a part of the processes by which the balance of the region is maintained or shifted". 


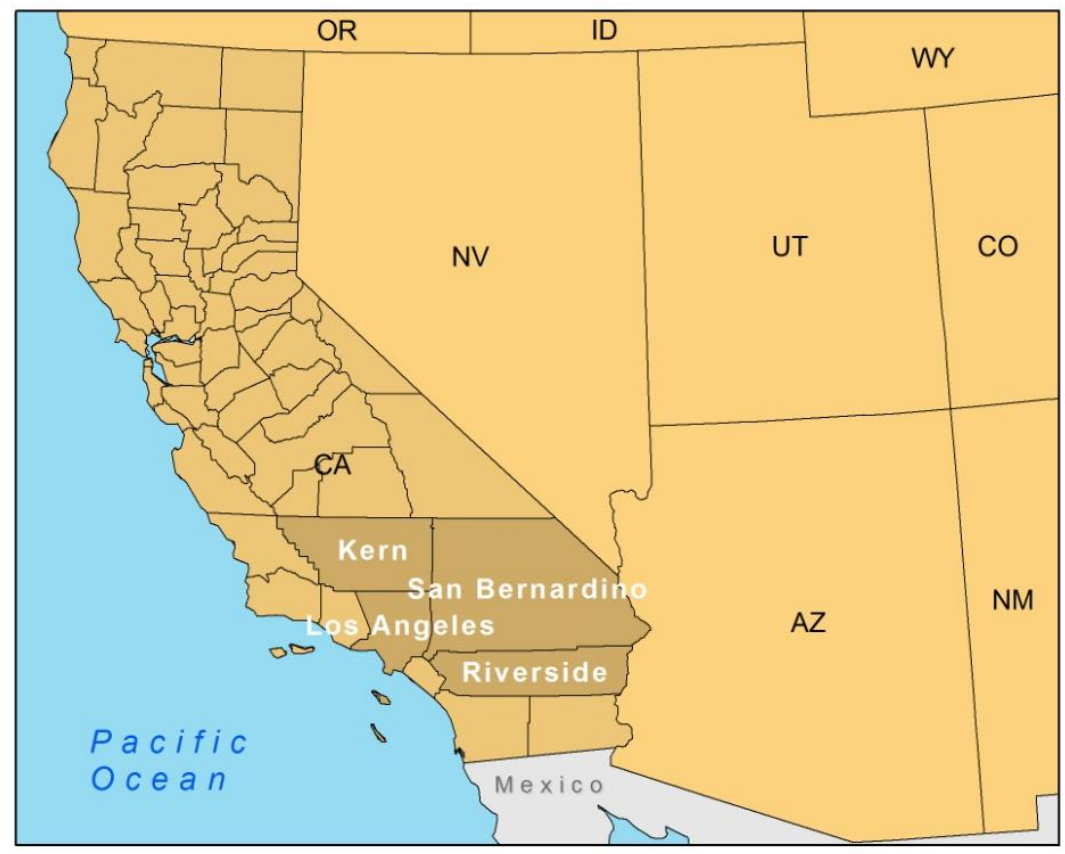

Figure 1. Study Area of Observations

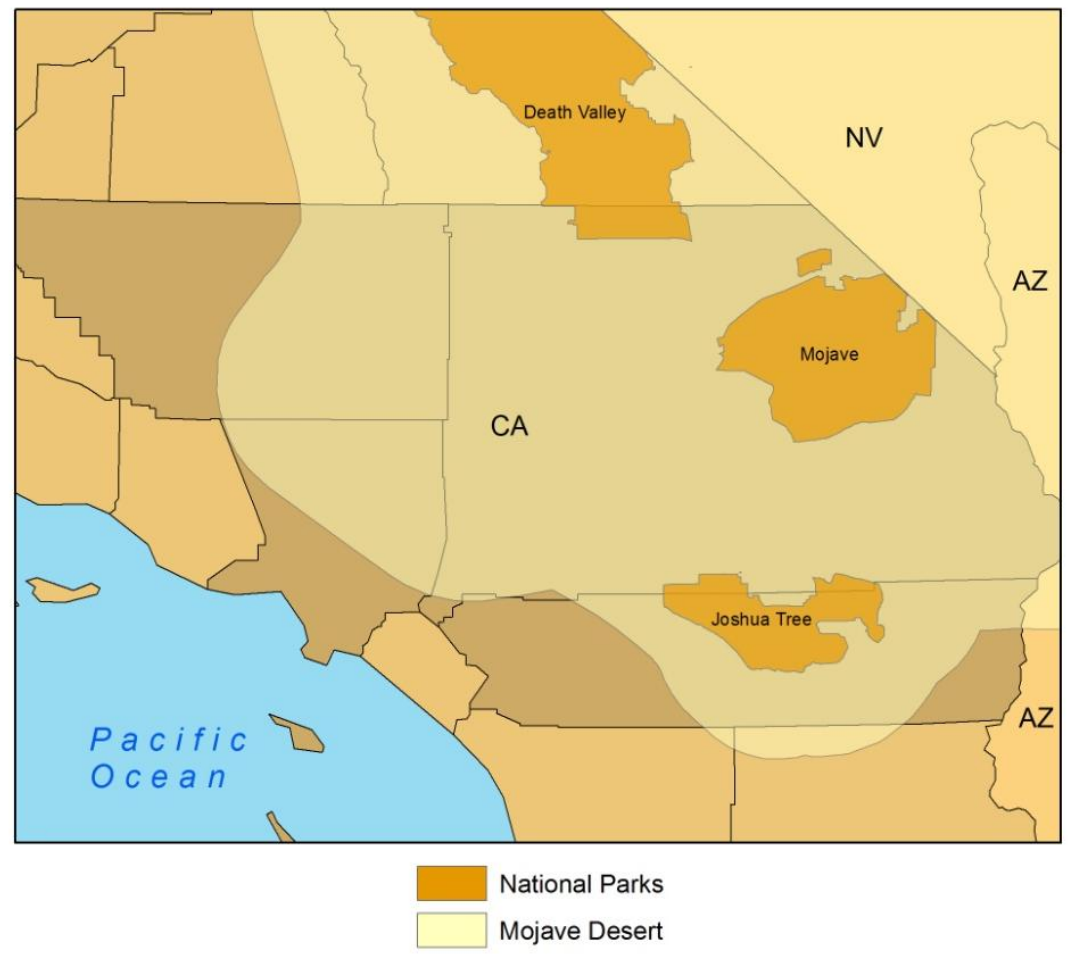

Figure 2. Study Area with National Parks and Mojave Ecoregion Boundary. 


\subsection{Problem Statement}

The common raven is an opportunistic predator (McIntyre, 2007). Even with human subsidies as an abundant food source, predation on the desert tortoise is still occurring. The data collected by McIntyre has been used to visualize the location of common raven nests and predation on the desert tortoise, but has not been used to determine if there is spatial correlation between common raven nests with predation and common raven nests without predation. Is there a relationship between the nests and surrounding features? For example, does a nest closer to an anthropogenic feature such as a landfill have the same amount of predation on the desert tortoise versus a nest not surrounded by anthropogenic food sources?

A step to help the desert tortoise population to recover is to control the common raven population. Several federal agencies have produced the Environmental Assessment to Implement a Desert Tortoise Recovery Plan Task: Reduce the Common Raven Predation on the Desert Tortoise (EA) (U.S. Fish and Wildlife Service, 2008). The EA provides several alternatives to reduce the common raven population. Some of the alternatives call for removal of ravens known to prey on the desert tortoise. The data collected by McIntyre could be used to observe areas found in her study with predation on the desert tortoise more closely. Determining whether there is a relationship between nest locations and surrounding features would help researchers make better informed decisions.

\subsection{Client}

The client for this project was Wendy McIntyre, Ph.D, Professor of Environmental Studies at the University of Redlands, in Redlands, California. McIntyre has collected data on raven predation on the desert tortoise over the past five years. This project is a continuation of McIntyre's work assisting the USFWS to develop a management strategy to regulate the raven population.

With this data, McIntyre wanted to determine if there was a spatial correlation between raven hot spot predation and surrounding features (natural and anthropogenic) in the Mojave Desert. She provided access to the raven data she had collected and provided expertise in the raven and desert tortoise habitat.

\subsection{Scope}

The scope of the project was to produce a usable and functional spatial database using the data collected by McIntyre. The data were stored in Microsoft Excel ${ }^{\mathrm{TM}}$ spreadsheets and statistical analysis could have been performed on this data alone; however, to be able to visualize and determine areas that have reoccurring predation, the data needed to be stored in a spatial database. ArcGIS Desktop 9.2, which is manufactured by Environmental Systems Research Institute, Inc. (ESRI), was used to create the geodatabase and conduct the associated analysis. Some of the applications determined relevance of the data, data input, editing, and manipulation. The deliverables were a geodatabase, a data dictionary, and spatial statistics on the raven predation hot spots. This project took approximately 500 hours to complete over a nine month period.

The client was responsible for providing the data collected and expertise on the raven population. McIntyre assisted in determining which spatial features, such as land use, 
might be factors in contributing to the different raven hot spot locations. The data she collected was used to complete various maps and visual analysis to determine correlations between hot spots. The original scope of the project was to run statistical applications, but there were limitations with both time and the content of the data.

\subsection{Objectives}

The primary objective of this project was to create a functional geodatabase that could be used to make basic inferences about the distribution of the raven population in the Mojave Desert. Specifically, the database would be useful for conducting simple spatial analysis to determine the relationship between the different raven predation hot spots.

A secondary objective was to create an efficient database that could be used for more sophisticated geospatial analysis. For example, if there was a correlation between the raven hot spots and land use patterns, then a database of this type could be used to support predictive modeling of raven habitats. This could lead to more effective sampling of raven nesting sites in the field. The end result would be to use these models to help the decision making processes on how to manage and reduce the raven population. This would also help find potential areas to relocate the threatened desert tortoise.

A personal objective was to build a geodatabase, and establish a professional relationship while gaining GIS experience. Environmental management is difficult because countless variables contribute to a balanced ecosystem. A geodatabase is one way to organize data and perform spatial analysis to discover and track solutions that can contribute to maintaining a stable environment. Many habitats have changed due to human development and new variables have been added that affect the raven life cycle. Incorporating GIS helps establish potential solutions to the problem. In order to accomplish the goal of stabilizing the raven and desert tortoise populations, an understanding of the environment had to be achieved first.

\subsection{Proposed Solution}

The proposed solution was to create a geodatabase and perform spatial analysis with the data collected by McIntyre. The intent was to organize the data to make it accessible so it could be used in the future to add data collected in the field. Setting up the data analysis may help future decision-making processes in wildlife management of the raven population.

The project produced a geodatabase using McIntyre's data. The deliverables were a geodatabase, maps, a tutorial, and spatial analysis on the raven predation hot spots. ArcGIS Desktop 9.2 was used to create the geodatabase and analysis. Some of the applications were used for determining relevance of the data, data input, editing, manipulating, etc.

The client was responsible for providing the data collected and expertise on the raven population. McIntyre assisted in determining what spatial features, such as land use, might be factors in contributing to the different raven hot spot locations. The data she collected was used to complete various analyses to determine correlations between hot spots. 


\section{Background and Literature Review}

The desert tortoise has many threats to its survival in the Mojave Desert. The common raven's predation is one danger. As explained by Boarman (1993):

"One important cause of increased mortality is predation by species with which the population has not coexisted until recently. These predatory populations may be either introduced species or native species that have experienced range expansions or population increases. Many management problems occur when the predator populations are subsidized by human activities; that is, when their populations increase or range expansions are facilitated by resources provided by humans".

The common raven is a native species to the Mojave Desert and is a subsidized predator. As described by Boarman (1997), a subsidized predator uses human resources for survival such as food and shelter. Humans have provided food sources that have helped increase the raven life span. Boarman also found that human subsidies help lower mortality by providing food when natural resources are low during a certain time period, and this helps increase the population.

This expansion of the raven population creates problems for maintaining the natural common raven population size (Boarman, 1993). Common ravens have more accessible areas in which to nest due to the presence of power towers and telephone towers, which have been erected in the critical habitat areas of the desert tortoise (McIntyre, 2007).

\subsection{Desert Tortoise}

The desert tortoise is a land turtle (Figure 3) (U.S. Fish and Wildlife Service, 2008). The population is divided into two groups: the Sonoran and the Mojave. The Sonoran population lives east of the Colorado River, while the Mojave population lives west of the Colorado River. The Mojave population is the population that is listed as a threatened species (U.S. Fish and Wildlife Service, 2008).

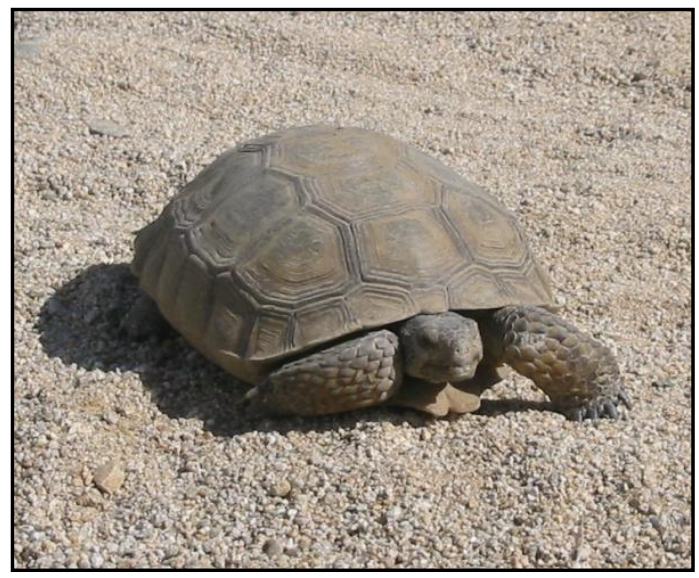

\section{Figure 3. Desert Tortoise (Provided by James Ciarrocca)}

The habitat for the desert tortoise ranges from southeastern California, parts of Nevada, Utah, and Arizona in the United States; and western Sonara and Sinaloa in Mexico (U.S. 
Fish and Wildlife Service, 2008). The USFWS also notes that the desert tortoise prefers sandy loam soils in the California desert and avoids plateaus, playas, sand dunes, and steep slopes.

The desert tortoise can have a life span of 50 years or more (U.S. Fish and Wildlife Service, 2007). Reproduction occurs between the ages of 12 to 20 years. The number of eggs lain ranges between 1 and 14 eggs, however; the number of eggs can be dependent on the amount of precipitation during the year. If there has been very little precipitation, females lay few eggs. A female can reproduce for several years after mating once with a male, because they can hold sperm for up to five years (U.S. Fish and Wildlife Service, 2007).

The desert tortoise is herbivorous, and their diet consists of wildflowers, grasses, and cacti (U.S. Fish and Wildlife Service, 2007; 2008). Desert tortoises' source of water is primarily from the plants they eat. They also use the bushes for shade and protection from predators (U.S. Fish and Wildlife Service, 2007). Desert tortoises live in burrows for hibernation and protection from the extreme environment. They are most active from March to June and from September to October (Boarman, 2001; U.S. Fish and Wildlife Service, 2007).

There are many other threats to the desert tortoise in addition to predation by ravens. There are direct threats such as motorized vehicles, predation, illegal collection and disease. Indirect threats include habitat loss from human inhabitation and toxins in exotic plants (Boarman, 2001).

\subsection{Common Raven}

The common raven is an omnivorous songbird (Figure 4). The article "Common Raven (Corvus corvax)" by Boarman and Heinrich (as cited in U.S. Fish and Wildlife Service, 2008) states the common raven population is found in North America, Europe, Asia, and North Africa (U.S. Fish and Wildlife Service, 2008). Figure 5 shows common raven habitat in California.

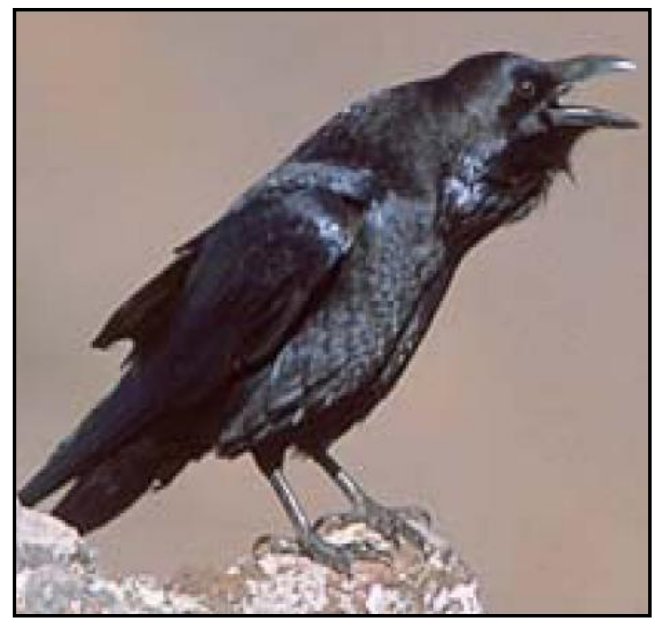

Figure 4. Common Raven (U.S. Fish and Wildlife Service, 2008) 


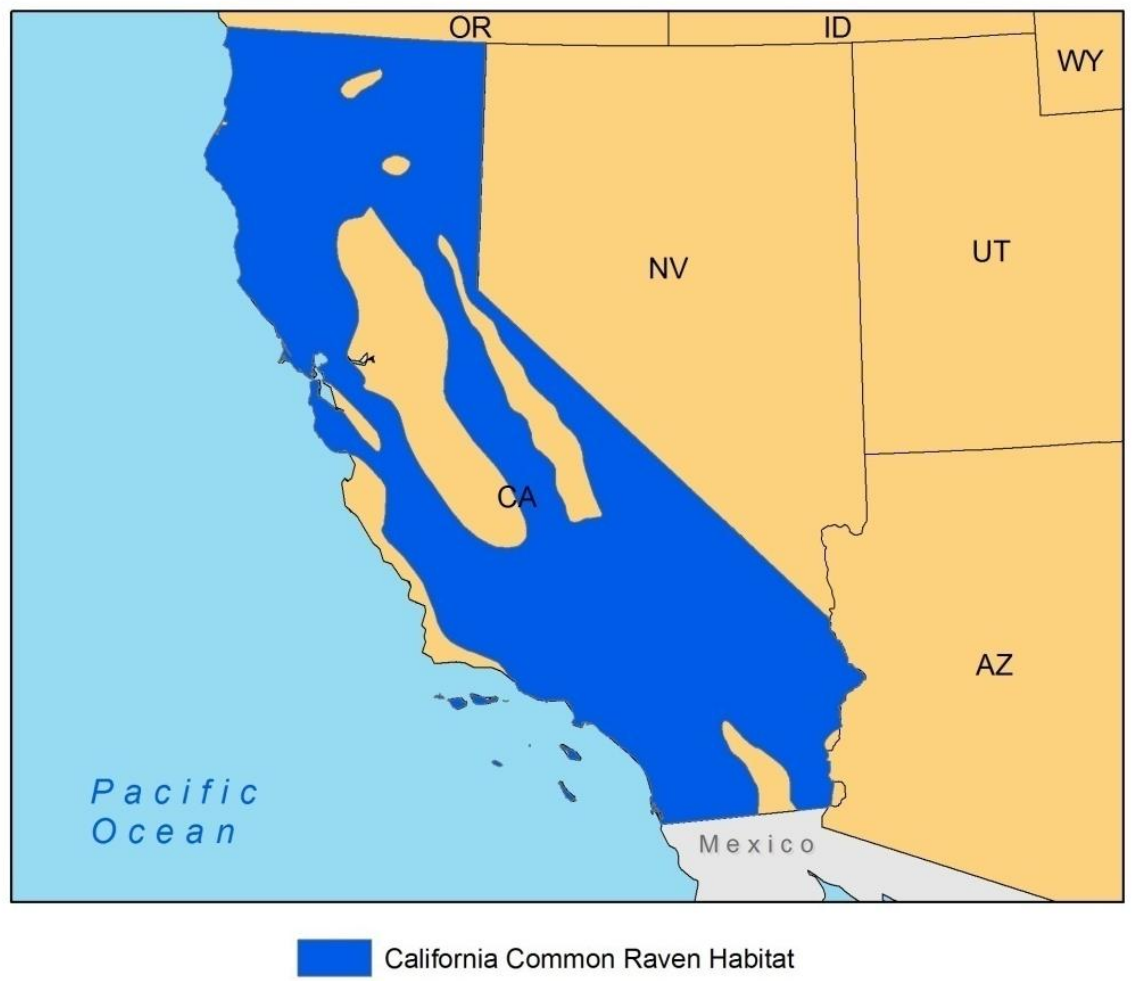

Figure 5. Common Raven Habitat within California

The diet of common ravens consists of grains, scavenged carcasses, live prey, and garbage (Boarman, 2003). Common ravens prey on juvenile desert tortoises as a source of food (Boarman, 2001).

In the winter, common ravens construct nests mostly of sticks and lay eggs from March to April. Ravens lay between three and seven eggs and average three chicks per nest per year (U.S. Fish and Wildlife Service, 2008).

The common raven population has increased 1,000 \% since the 1960s (Boarman, 1997). Much of this increase can be attributed to human intervention. Common ravens are opportunistic feeders and feed on subsidies provided by humans. These subsidies provide ravens with food, water, and shelter, which "increases their chance of survival during times when resources are limited" (Boarman, 1997). With a longer life cycle, the ravens have "greater reproductive success and expand their geographic range" (Boarman, 1997).

\subsection{Study Area}

The study area consists of four counties within the southern California area covered by the Mojave Desert: Kern, Los Angeles, Riverside, and San Bernardino (Figure 6). Some of the study sites were a continuation of common raven observation locations chosen by Dr. William Boarman who provided bird nest data to McIntyre. Dr. McIntyre then visited previous sites observed by Dr. Boarman and also observed new sites within the same study area (McIntyre, personal communication, June 6, 2008). 


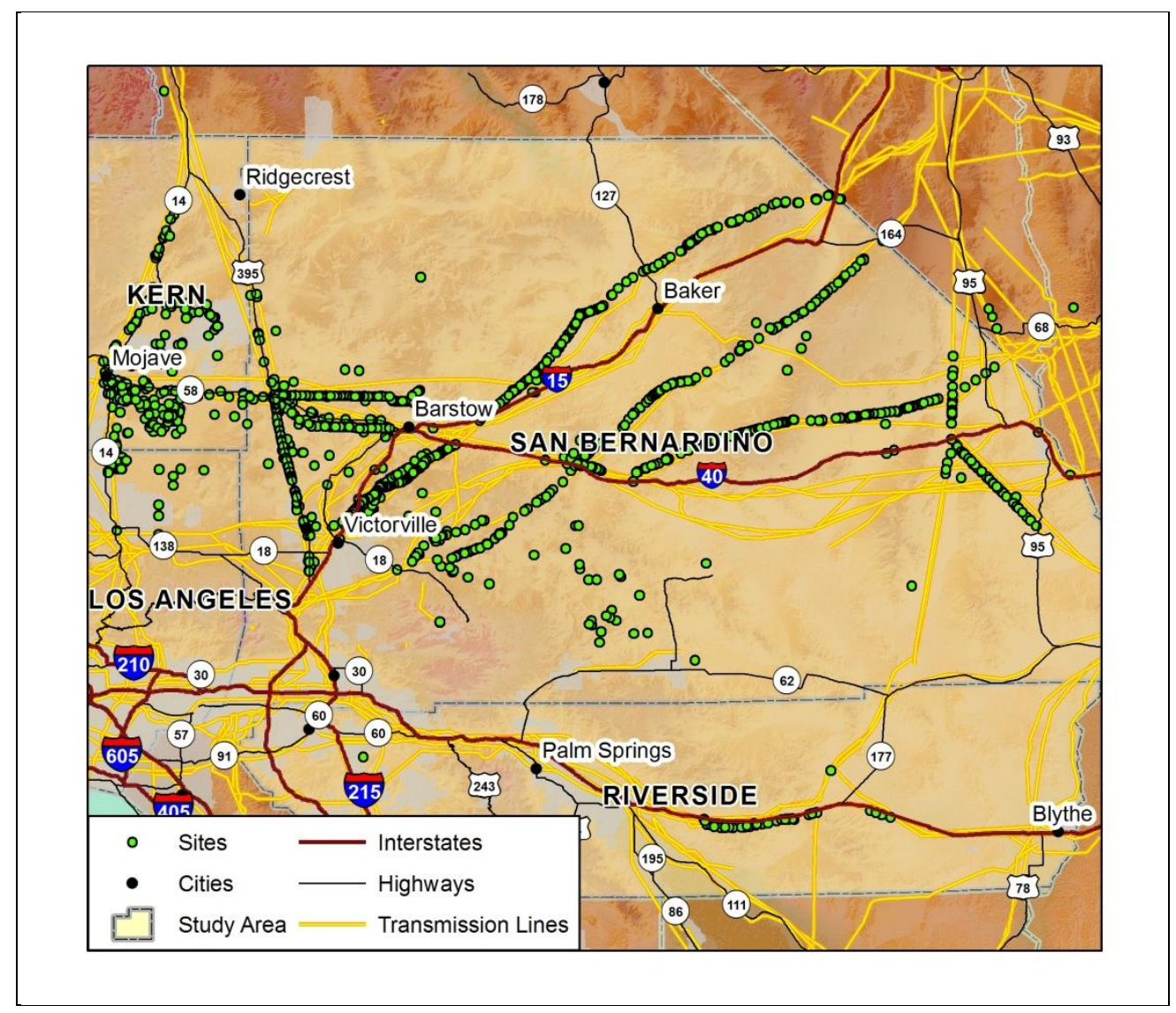

\section{Figure 6. Map of study area}

\subsection{Literature Review}

This section discusses studies that have used GIS for habitat studies and studies that have analyzed common ravens and desert tortoises. GIS in habitat studies provides a way to visualize data collected in studies; however, it is difficult to create a normalized spatial database with data tracking sites over time. A normalized database avoids data redundancy (Egenhofer, Frank, \& Hudson, 1997). Locations that are observed over time may have the same spatial location and have multiple observations. To prevent data repeating such as the location in the database, separating the spatial from observations reduces redundancy.

\subsubsection{Database}

The data provided by McIntyre needed to be implemented into a database. The database needed to be simple for a user with little GIS experience. Studies have implemented tracking data into geodatabases but these studies came across limitations with creating a normalized database.

A project for the Consumnes River Preserve in California, required data to be implemented into a personal geodatabase to store 20 years of records (Hogle, Viers, \& Quinn, 2007). Monitoring occurred periodically at the restoration sites and the data was implemented into a geodatabase to visualize active and non-active restoration projects. 
The project divided the data into features and also put data into tables referenced to the feature by common site code. This project used joins to link features and tables; however used Access to link one-to-many joins (Hogle et al., 2007). The project did not state if and how ArcMap was used to visualize the data joined in Access with a one-to-many link in ArcMap.

Another habitat project containing historical data implemented it into a relational database. The riparian habitat was threatened by invasive plants in California. This project needed to implement the data into a database to track vegetation patches (Viers et al., 2005). The relational database consisted of two tables dividing the data based upon "preserved snap shots for each survey year" and "snap shots for patch's history" such as creation and patch death with PatchID attribute linking the tables together (Viers et al., 2005). This design was not used after testing because it was not efficient to maintain. This project then created a database which stored data in feature datasets by year for each field season (Viers et al., 2005).

The conceptual design and test design for McIntyre's data needed to be normalized by separating the spatial feature from the observations collected over the past 18 years, but had limitations because ArcMap does not symbolize or query one-to-many joins. The design resulted in organizing the data into one feature class.

\subsubsection{Analysis}

GIS has been used to quantify the common raven predation threat on the desert tortoise at Fort Irwin, California, located in the Mojave Desert (McIntyre, Leuteritz \& Kumler, submitted). The study area was a translocation area for the desert tortoise. The translocation areas were studied to examine the common raven predation. This study "used point counts to determine relative abundance of ravens" to produce a spline-withbarriers density surface map (McIntyre, 2007). This analysis determined what parts of the translocation areas had high and low densities of common ravens. The results showed that anthropogenic sites were areas of higher raven populations (McIntyre, Leuteritz \& Kumler, submitted).

A predictive empirical model was developed based on a study of the desert tortoise habitat in the Mojave Desert (Anderson, et al., 2000). The data used for the model came from field surveys and spatial databases. GIS was used to organize and display the datasets. The study used GIS referenced data of various layers such as soil units and tortoise observations (Anderson, et al., 2000). The concept of a predictive model was chosen due to the large areas that tortoises may inhabit. The analysis in the study for the model targeted a smaller sampling area with tortoises, and this technique could be used to develop the model (Anderson, et al., 2000). This study provided habitat requirements of endangered species, but this analysis is for more than just endangered species. A predictive model is a useful tool in wildlife management. When targeting populations, predictive modeling could help researchers find better sampling methods in order to discover more raven predation locations and implement a management plan.

Predation is a natural process and Boarman (1997) states that there are two types of predation. There is predation that contributes to a "natural level of mortality," and there is predation that causes an abnormally high mortality rate. A study by the U.S. Forest 
Service in Corvallis, Oregon, used basic applications of GIS to find potential habitation areas of the Coho salmon population, which has decreased due to hunting and human development such as straightening rivers (Lang, 1998). These GIS applications consisted of overlaying features needed for the Coho salmon to survive. The concept behind finding potential areas of Coho salmon habitation was used in this study as well. Targeting locations of populations is essential to finding useful management policies in order to maintain a balance of life.

GIS is a tool that can be used for examining the spatial relationships between ravens and desert tortoise. To further the exploration of the raven population, various spatial analysis techniques could be performed to suggest why ravens are in specific locations in the desert and determine what features are located in these areas that may contribute to these hot spots. Generating a population density map would be beneficial to show where intense raven locations are, and it could also be used as a tool to manage the raven population.

A predictive model would have been a beneficial tool to find potential areas of raven predation in the Mojave Desert, but the data collected by McIntyre needed to be implemented into a geodatabase and then analyzed. There was not time to create a predictive model. Also, several factors would have been missing. The location of every single Joshua tree, cliff, power tower, telephone pole, and other tall anthropogenic features are not known. Points of these features would be necessary to be able to predict sites where ravens might nest; only then could the known nest sites be used to predict suitable locations for ravens. The data analysis, as in the Fort Irwin project, was a method to find relationships between the raven hot spots and surrounding features. Understanding the locations of raven predation is important to figure out a method to reduce the raven population. 


\section{Requirements Analysis}

The requirements for this project were determined through discussions with McIntyre and James Ciarrocca, MS GIS program, at the University of Redlands. The importance of variables in the common raven and desert tortoise habitats were discussed. The complexity of the project was based on the client and how the client wanted to be able to use the geodatabase. The client needed to run queries and be able to visualize the locations of the observations.

The geodatabase for the client is a single user and is stored in the Redlands Institute server, which is where the client stores her data. The functionality of the project needed to be user friendly, and it contains documentation with an explanation of the data storage, location of data, and spatial applications that can be performed with the data. The project was to use standard tools within ArcGIS and not customized programming tools. The metadata for the data would have to be compliant with the metadata standards established by Federal Geographic Data Committee (FGDC).

In Table 1, a use case is presented of how the user can implement data and use the geodatabase. The use case helped provide an overview of what was needed and what requirements were necessary for the project. It describes what the client wanted to be able to use the data she has collected.

Table 1. Raven Location Use Case

\begin{tabular}{|l|l|}
\hline Use Case Name & Raven Location \\
\hline Description & $\begin{array}{l}\text { Analyze the distance from raven locations to } \\
\text { anthropogenic or natural features }\end{array}$ \\
\hline Actor & $\begin{array}{l}\text { Professor from the Environmental Studies } \\
\text { Department at the University of Redland. }\end{array}$ \\
\hline Trigger & $\begin{array}{l}\text { Professor has collected new raven sites and she } \\
\text { inputs the data into the geodatabase, then runs } \\
\text { spatial analysis on the sites and surrounding } \\
\text { features }\end{array}$ \\
\hline Major Inputs & Raven locations \\
\hline Major Outputs & $\begin{array}{l}\text { Distance of raven site locations from } \\
\text { anthropogenic or natural features }\end{array}$ \\
\hline Normal Process Steps & $\begin{array}{l}\text { 1. Create feature with raven site locations in the } \\
\text { file geodatabase } \\
\text { 2. Create metadata of the raven site locations } \\
\text { 3. Input raven site feature in Near tool located in } \\
\text { the ArcGIS Toolbox } \\
\text { 4. Run analysis }\end{array}$ \\
\hline Preconditions & $\begin{array}{l}\text { Raven site locations had previously been in Excel } \\
\text { spreadsheet }\end{array}$ \\
\hline Post-condition & $\begin{array}{l}\text { Raven site locations are feature classes with } \\
\text { complete metadata in the geodatabase }\end{array}$ \\
\hline Assumptions & $\begin{array}{l}\text { Professor is capable of performing simple spatial } \\
\text { analysis applications }\end{array}$ \\
\hline
\end{tabular}




\subsection{Functional Requirements}

The functional requirements listed in Table 2 are necessary for the project to succeed. These requirements describe the behavior of the project and were based on the client's needs for the project. The client needed to be able to perform queries to select observations with common ravens and desert tortoise shells. Then analyze the selected data with visual analysis and spatial analysis.

Table 2. Functional Requirements

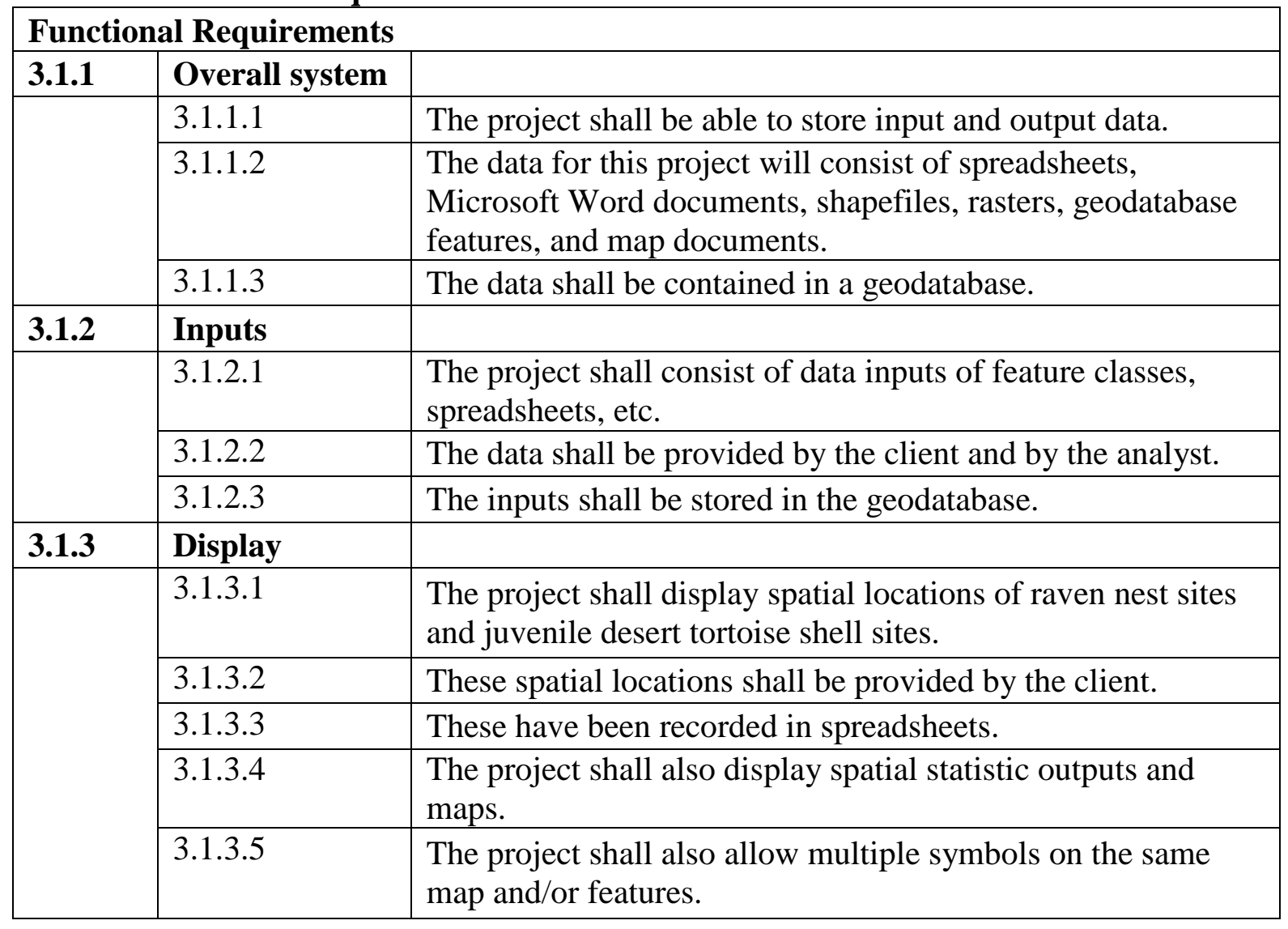




\begin{tabular}{|c|c|c|}
\hline \multirow[t]{6}{*}{ 3.1.4 } & Applications & \\
\hline & \begin{tabular}{|l|l|}
3.1 .4 .1 \\
\end{tabular} & The project shall run spatial statistic applications. \\
\hline & 3.1 .4 .2 & $\begin{array}{l}\text { The spatial analysis shall be performed with the data } \\
\text { provided by the client. }\end{array}$ \\
\hline & 3.1 .4 .3 & $\begin{array}{l}\text { The spatial analysis shall determine if there are correlations } \\
\text { between raven hotspot locations as well as analyze raven sites } \\
\text { with their surrounding features. }\end{array}$ \\
\hline & 3.1.4.4 & $\begin{array}{l}\text { The project shall allow the user to define the data features' } \\
\text { reference system. }\end{array}$ \\
\hline & 3.1 .4 .5 & $\begin{array}{l}\text { The output of the applications shall be stored in the } \\
\text { geodatabase. }\end{array}$ \\
\hline \multirow[t]{5}{*}{ 3.1.5 } & Queries & \\
\hline & 3.1 .5 .1 & $\begin{array}{l}\text { The project shall be able to execute spatial queries with the } \\
\text { raven, desert, tortoise and surrounding features data in the } \\
\text { geodatabase. }\end{array}$ \\
\hline & 3.1 .5 .2 & $\begin{array}{l}\text { The queries shall select the feature's attributes from the } \\
\text { feature's attribute table. }\end{array}$ \\
\hline & 3.1.5.3 & $\begin{array}{l}\text { The project shall be able to let the client sort through the } \\
\text { attributes from the attribute table from the query results. }\end{array}$ \\
\hline & 3.1.5.4 & $\begin{array}{l}\text { The queries may be used with the applications and may be } \\
\text { necessary to run queries to apply to specific applications. }\end{array}$ \\
\hline \multirow[t]{2}{*}{ 3.1.6 } & Toolsets & \\
\hline & 3.1 .6 .1 & $\begin{array}{l}\text { The project shall have toolsets run queries and spatial } \\
\text { analysis applications. }\end{array}$ \\
\hline \multirow[t]{5}{*}{ 3.1.7 } & Outputs & \\
\hline & 3.1 .7 .1 & $\begin{array}{l}\text { The project shall output query results in soft copy or hard } \\
\text { copy in reports, screen shots, and maps. }\end{array}$ \\
\hline & 3.1 .7 .2 & $\begin{array}{l}\text { The project shall output spatial statistic results in soft copy or } \\
\text { hard copy in reports, screen shots, maps. }\end{array}$ \\
\hline & 3.1 .7 .3 & The project shall output defined referenced data in soft copy. \\
\hline & 3.1.7.4 & The project shall output maps in soft copy and hard copy. \\
\hline
\end{tabular}

\subsection{Nonfunctional Requirements}

The nonfunctional requirements presented in Table 3 describe the characteristics and properties of the project. The majority of the nonfunctional requirements were based on the accessibility to the Redlands Institutes network. The client has access and stores her data in the network. 
Table 3. Nonfunctional Requirements

\begin{tabular}{|c|c|c|}
\hline \multicolumn{3}{|c|}{ Nonfunctional Requirements } \\
\hline \multirow[t]{6}{*}{ 3.2.1 } & Storage & \\
\hline & 3.2.1.1 & A property of the project requires the system to have sufficient storage. \\
\hline & 3.2.1.2 & The storage for the project shall be contained in a geodatabase. \\
\hline & 3.2.1.3 & The geodatabase shall be used in ArcGIS Desktop 9.2. \\
\hline & 3.2.1.4 & $\begin{array}{l}\text { The design of the geodatabase shall be constructed for a beginner in } \\
\text { Geographic Information Systems (GIS). }\end{array}$ \\
\hline & 3.2.1.7 & $\begin{array}{l}\text { The project shall also have a sufficient workstation to execute the } \\
\text { overall project functionally. }\end{array}$ \\
\hline \multirow[t]{3}{*}{3.2 .2} & Security & \\
\hline & 3.2 .2 .1 & $\begin{array}{l}\text { The project shall be stored in a geodatabase in the Redlands } \\
\text { Institute network. }\end{array}$ \\
\hline & 3.2 .2 .2 & The security of this network fits the client's needs for security. \\
\hline \multirow[t]{4}{*}{3.2 .3} & Accessibility & \\
\hline & 3.2.3.1 & $\begin{array}{l}\text { The project shall have accessibility to the geodatabase through the } \\
\text { Redlands Institute network. }\end{array}$ \\
\hline & 3.2 .3 .2 & $\begin{array}{l}\text { The geodatabase shall be designed to be read and used by a user with } \\
\text { little GIS experience. }\end{array}$ \\
\hline & 3.2.3.3 & The project shall allow one user. \\
\hline \multirow[t]{3}{*}{3.2 .4} & Documentation & \\
\hline & 3.2.4.1 & $\begin{array}{l}\text { The project shall have documentation of how the project was designed } \\
\text { and implemented and its results. }\end{array}$ \\
\hline & 3.2.4.2 & The project shall also have documentation of a data dictionary. \\
\hline \multirow[t]{2}{*}{3.3 .5} & Standards & \\
\hline & 3.2.5.1 & $\begin{array}{l}\text { The project shall have metadata that will be compliant with } \\
\text { the FGDC requirements. }\end{array}$ \\
\hline
\end{tabular}

The base data layers (landfills, transmission lines, habitats, etc.) used in this project were derived requirements. After several meetings with the client, these layers were added to the project because they are an essential part in the landscape of the common raven population.

\subsection{Data}

The geodatabase was dependent on the data provided by McIntyre. The geodatabase needed to be simple. The data required editing and maintenance, and the data needed to be compliant for a GIS. The data sources for this project are found in Appendix B.

The client provided the majority of the data. The client did not have transmission lines, or active landfills. The transmission lines were downloaded from the US Geological Survey (USGS) Sagemap. The active landfills were acquired through County of Kern Engineering Survey Services Department, County of San Bernardino Solid Waste 
Management Division, Los Angeles County Department of Regional Planning, and Riverside County Waste Management Department. The data from Kern County, Los Angeles County and Riverside County were shapefiles. The landfill data from San Bernardino County were CAD files.

The digital elevation model (DEM) was obtained from the Redlands Institute. The DEM was created by the USGS Center for Earth Resource Observation and Science (EROS), National Aeronautics and Space Administration (NASA), National GeospatialIntelligence Agency (NGA), and ESRI. The hillshade was created from the DEM.

The design of the geodatabase was based on the nest data. The nest data was provided by McIntyre in .dbf file format and on Microsoft Excel spreadsheets. The data provided had been collected from 1990 to 2008. Data collected from 1990 to 2004 was provided to McIntyre by Boarman. From 2004 to 2008, McIntyre and students from the Environmental Studies Department at the University of Redlands observed raven nests during spring and summer. (B.M. McIntyre, personal communication, June 30, 2008). Data was collected during that time of year because it is breeding season for both common ravens and desert tortoises. It is also when the common raven and desert tortoise are the most active (U.S. Fish and Wildlife Service, 2008). Most of the observed sites were under power towers (B.M. McIntyre, personal communication, June 30, 2008).

The site observations from 2004 to 2008 were dependent on funding. In 2004, the nests observed included both new sites and those sites previously observed by Boarman. In 2005 , funding was about half of what it had been the previous year. Sites were selected based on data of predation in 2004. In 2006, there was no funding, so McIntyre taught a short field course during the month of May, 2006 at the University of Redlands, and the student's fees paid for the study's expenses. However, the field truck was damaged in an accident and, consequently, the observations were limited. In 2007, McIntyre taught an independent study course for which students observed sites, but there was an extreme drought. This is believed to be a reason for little tortoise activity for that year. McIntyre received funding for 2008 through the University of Redlands. Sites were selected based upon predation from previous years. The sampling was not the same every year, but it helps management see where predation has been reoccurring (B.M. McIntyre, personal communication, June 30, 2008).

In the conceptual design, the nest data was broken down into a Sites feature class and an Observations table. The Sites feature class contains the elements that remain static throughout the years. For example, the location of a nest may be on a power tower. The power tower's area will not change unless it is torn down, and the structure of the power tower will not change. Therefore, the area where the power tower is found, the power tower structure number, the type of power tower (slab, spindle, flat top, etc.), and the Universal Transverse Mercator (UTM) coordinates were used for the attributes of the Sites feature class. The UTM coordinates were collected from a GPS used in the field during nest observations. A GPS was placed below the nest and the UTM coordinates were recorded.

The Observations table used the dynamic data. For instance, the observations that change every year are the following: date, status of nest presence, shells present, pellets present, 


Table 4.Database features
\begin{tabular}{|l|}
\hline Features \\
\hline Common Raven Habitat \\
Continents \\
Critical Habitat Units \\
DEM \\
Desert Tortoise Habitat \\
Highways \\
Hillshade \\
Lakes \\
Landfills \\
Major Cities \\
Military Lands \\
Mojave Desert \\
Power Lines \\
Reservoirs \\
Rivers \\
U.S. National Parks (southern \\
California) \\
Urban Areas \\
U.S. Counties \\
U.S. States \\
\hline
\end{tabular}

The geodatabase with the one-to-many design would have consisted of one relationship class. A composite relationship class was chosen. A composite relationship is a one-toone or one-to-many relationship. When the parent record is deleted, the child records related are also deleted (ESRI, 2006b). The Observations table was dependent on the Sites feature class. Figure 8 from ArcGIS Desktop Help shows an example of how a composite relationship works. When Parcel_ID 129 is deleted from the origin table, Parcel_ID records are deleted in the destination table.

\section{Composite: Origin objects control de stination objects

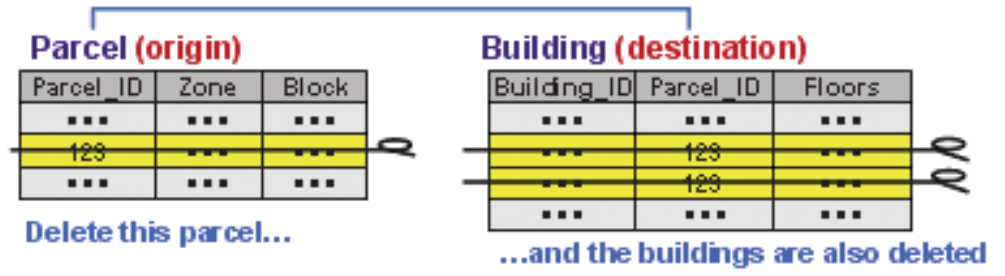

Figure 8. Composite Relationship Diagram (ESRI, 2006b)

A composite relationship class was chosen because the observations are dependent on the Sites feature class. An observation does not occur unless there is a site to observe. The cardinality was one-to-many. There can be many observations for one site. The MasterID 
attribute was the primary key for the Sites feature class and the MasterID attribute was the foreign key for the Observations table (Figure 9).

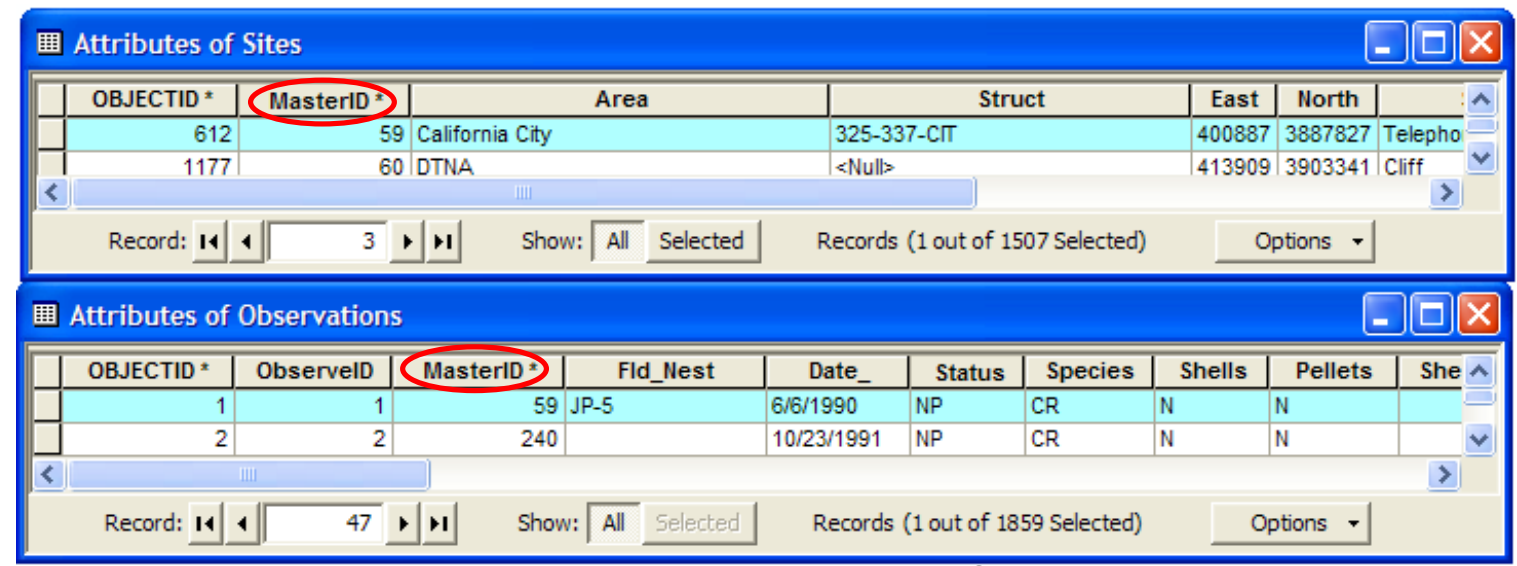

\section{Figure 9. Primary and Foreign Keys}

The primary of the origin table links to the foreign key of the destination table. Figure 10 displays the SiteObservations relationship class properties. 


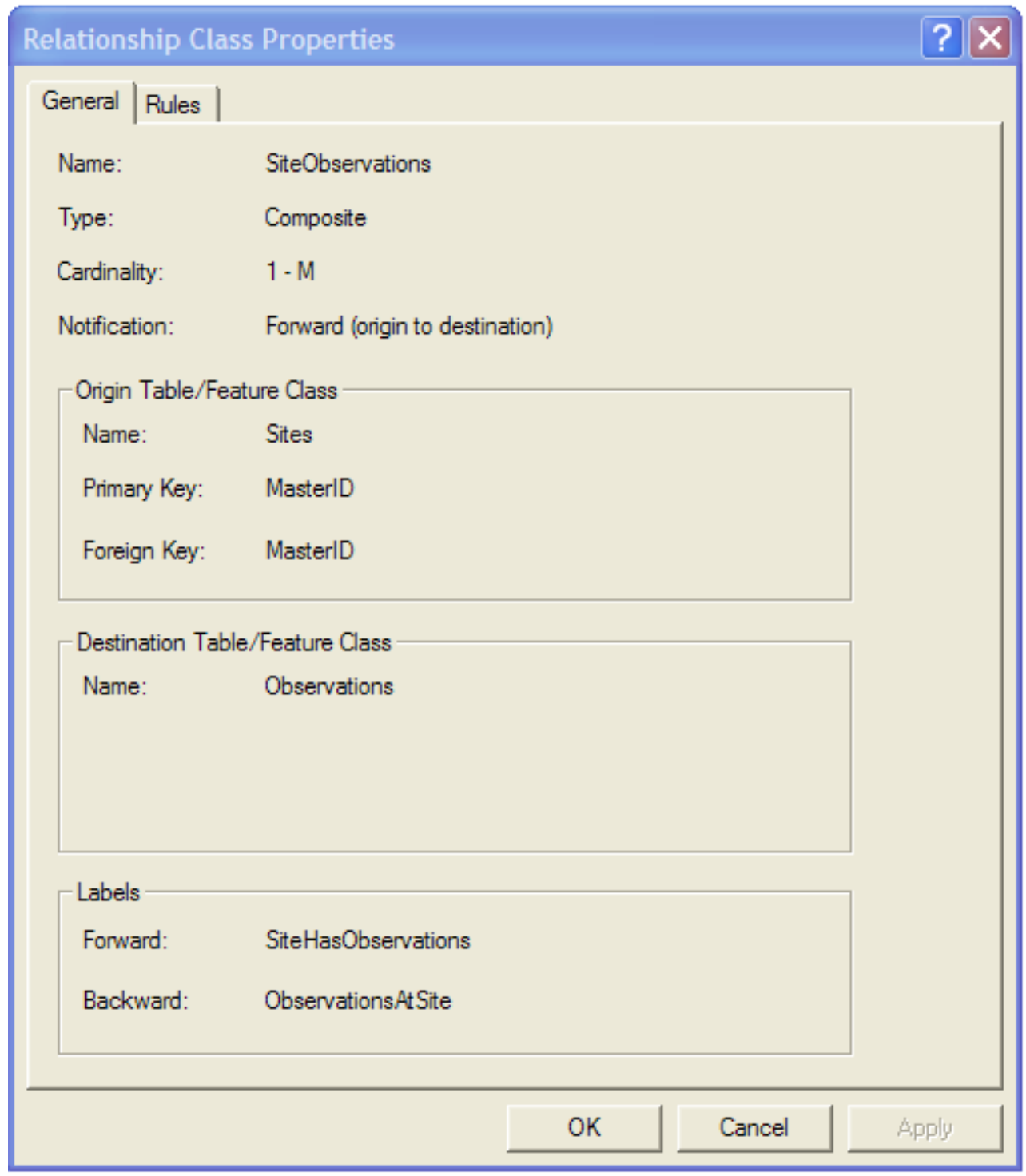

\section{Figure 10. Relationship Class Properties}

Unfortunately, this design cannot be used in ArcGIS without customization and programming steps. The project scope was to use ArcGIS without customization and use standard tools and ArcCatalog to develop the geodatabase. This design would have been more efficient in a data management design; however, with ArcMap, a join between tables has to be a one-to-one or many-to-one design (ESRI, 2006a). This eliminated splitting the data into two tables. The one-to-many design could have been used if symbolization was not needed but the project required maps for visual analysis. To symbolize relationships, a join function is necessary to symbolize data but it has to be a one-to-one or many-to-one relationship.

After consideration of the data that was most beneficial to visualizing the areas and performing queries, one table was built with all the data. The feature has redundant data with multiple points for one site; however, to be able to symbolize data by year, number of shells, etc., the data had to have a spatial component. Combining the data into one table allowed for the user to query by year, number of shells, etc., and the user would be 
able to symbolize the data or run analysis. The other features were used also for visualizing the location of the Sites feature class.

All data was projected to UTM Zone 11 North American Datum 1983. The California State Plane System was not used because Los Angeles County, Kern County, and San Bernardino County are in California State Plane Zone V and Riverside County is in California State Plane Zone VI. The metadata is compliant with the FGDC standards. 


\section{Design}

This section discusses the system description, system architecture, database design, and software design. A file geodatabase was chosen to store the data.

A geodatabase is an ESRI GIS database. There are three types of geodatabases: personal, file, and ArcSDE. Properties of each geodatabase are listed in Table 5. This table was acquired from ArcGIS Desktop Help.

Table 5. Types of Geodatabases (ESRI, 2006c)

\begin{tabular}{|l|l|}
\hline Type & Description \\
\hline Personal geodatabase & - Is stored in Access \\
& - Has a 2 GB size limit, but effective size is 250 to 500 \\
& - UB per geodatabase \\
& - Supports a single editor and a few readers \\
& - Has no versioning support \\
\hline File geodatabase & - Is stored in a file folder \\
& $\begin{array}{l}\text { - Any platform } \\
\text { - Supports a single editor and a few readers }\end{array}$ \\
\hline ArcSDE geodatabase & - Is stored in a RDBMS (Oracle, SQL Server, DB2, \\
& - Informix) \\
& - Upports many editors and many readers \\
& - Provides versioning and multiuser support \\
\hline
\end{tabular}

The client wanted to be able to use the data collected in a GIS. A file geodatabase was chosen based on the client's requirements. A file geodatabase provided more space and could be expanded in the future. The geodatabase needed to be simple and not require multiple users; therefore, ArcSDE techniques and development were not explored.

\subsection{System Description}

The project consisted of a geodatabase that stored data collected by the client and analyst. The geodatabase needed to be accessible for a user with little GIS experience. The data had to be projected to a reference system suitable for the type of analysis performed. Analysis was performed through queries and symbolizing attributes. The project had outputs of queries results and maps.

\subsection{System Architecture}

The data was implemented into a file geodatabase that was created using ArcCatalog in ArcGIS Desktop 9.2. ArcGIS Desktop is a GIS software package manufactured by ESRI and was installed on a Dell Precision M4300, a stand-alone workstation. Through ArcGIS, the metadata was created and edited, and visual analysis was performed on the data. The project used only tools found with ArcGIS Desktop. The data and product 
output are reports, maps, and output data from the analysis. ArcGIS Desktop, Microsoft Office 2007 (Word, Excel, PowerPoint, and Visio), WinRAR, and Acrobat Adobe Reader 8 are the software packages that were used to create the reports, maps and run analysis. Future work may contain output data from spatial analysis which would be stored in the geodatabase. The system architecture is shown in Figure 11, with the data input, data editing and maintenance, data analysis, and data output. The diagram shows where each process took place in the computer and the software packages that were used to run the processes.

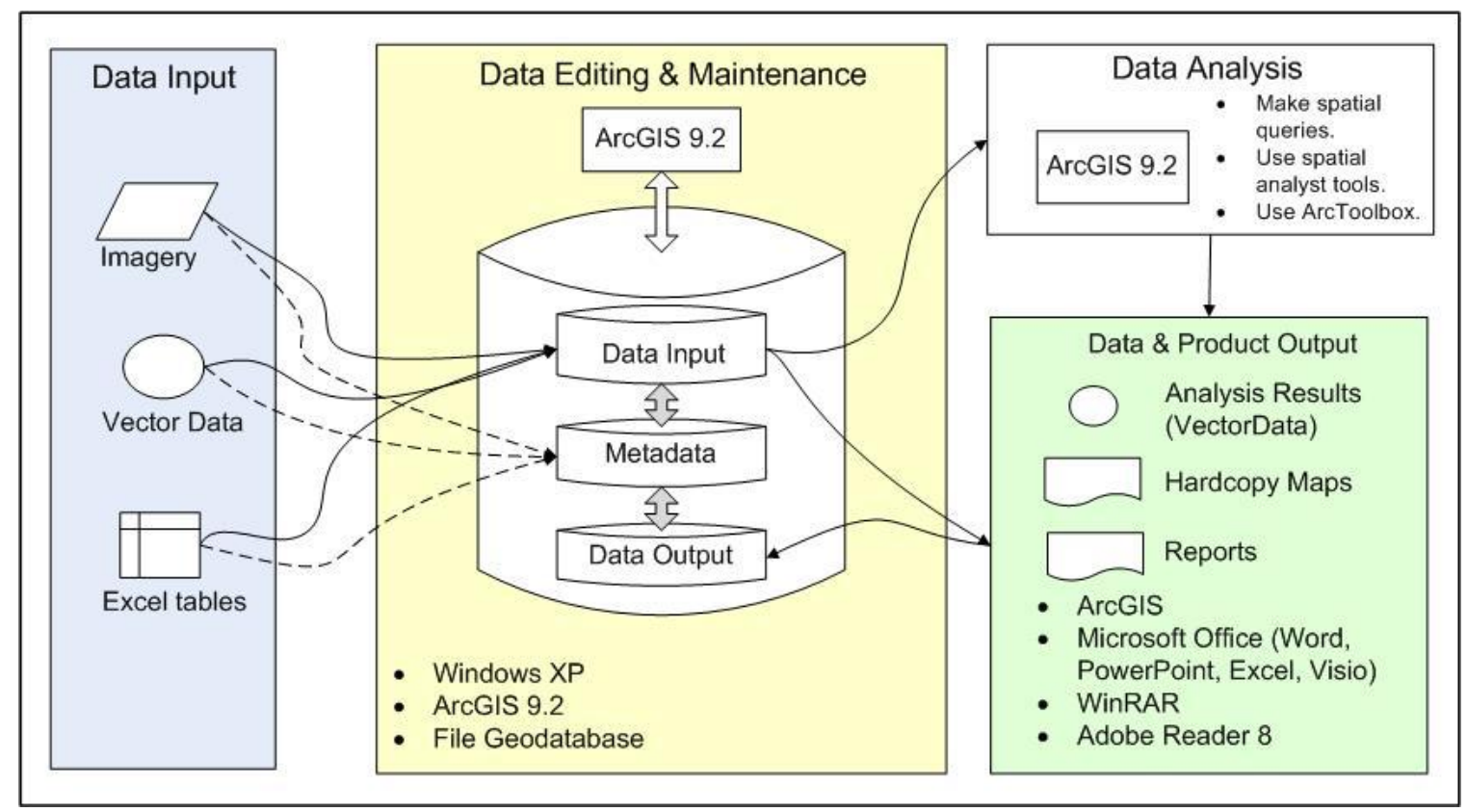

\section{Figure 11. Raven Project System Architecture}

\subsection{Database Design}

The database was designed for use by the client, a user with limited GIS experience. The overall design of the geodatabase contains five feature datasets: Administrative, Analysis, Biological, Hydro, and Transportation. Figure 12 illustrates the database design for a geodatabase in ArcGIS. 


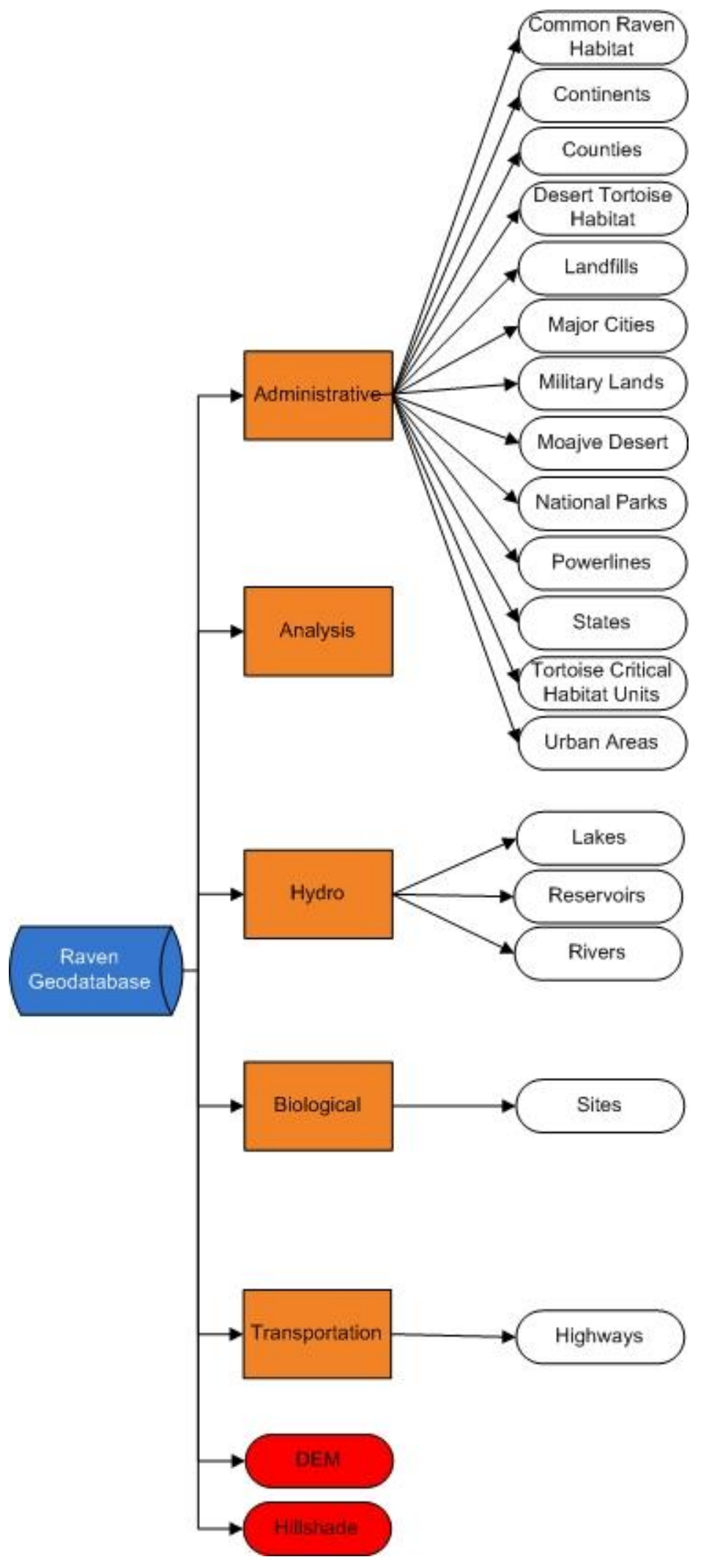

Figure 12. Geodatabase Design 
In Table 6, each feature is listed with its location in reference to its feature dataset and type of feature class. The data is stored in a file geodatabase that provides one terra byte (TB) of space per dataset.

The simplicity of the database is important for the type of user for whom it was designed. The user has some experience with GIS but is not proficient in GIS. The design for the geodatabase was constructed so the user could easily access the data, input data, and retrieve output data.

Table 6. Data Characteristics

\begin{tabular}{|l|l|l|}
\hline DATA & FEATURE & TYPE \\
\hline Administrative & Feature Dataset & \\
\hline Common Raven Habitat & Feature Class & Polygon \\
\hline Continents & Feature Class & Polygon \\
\hline Desert Tortoise Habitat & Feature Class & Polygon \\
\hline Landfills & Feature Class & Polygon \\
\hline Major Cities & Feature Class & Point \\
\hline Military Lands & Feature Class & Polygon \\
\hline Mojave Desert & Feature Class & Polygon \\
\hline National Parks (southern California) & Feature Class & Polygon \\
\hline Power Lines & Feature Class & Polyline \\
\hline Tortoise Critical Habitat Units & Feature Class & Polygon \\
\hline U.S. Counties & Feature Class & Polygon \\
\hline U.S. States & Feature Class & Polygon \\
\hline Urban Areas & Feature Class & Polygon \\
\hline Hydro & Feature Dataset & \\
\hline Lakes & Feature Class & Polygon \\
\hline Reservoirs & Feature Class & Polygon \\
\hline Rivers & Feature Class & Polyline \\
\hline Biological & Feature Dataset & \\
\hline Sites & Feature Class & Point \\
\hline Transportation & Feature Dataset & \\
\hline Highways & Feature Class & Polyline \\
\hline DEM & & Raster \\
\hline Hillshade & & Raster \\
\hline
\end{tabular}

\subsection{Software Design}

The design of the project required specific commercial software to fulfill the requirements. The software packages were used on the Windows XP operating system. In Table 7, a software use case diagram shows how each software package could be used by the user. This project used standard applications and did not have the user involved in creating customization, configuration, integration, or programming. 
Table 7. Software Use Case Diagram

\begin{tabular}{|l|l|}
\hline SOFTWARE & FUNCTIONS \\
\hline Microsoft Office 2007 & Create reports \\
\hline Word & Create and read database files \\
\hline Excel & $\begin{array}{l}\text { Create presentation for MIP Defense } \\
\text { Include ESRI Conference Proceedings }\end{array}$ \\
\hline PowerPoint & Create diagrams such as database design \\
\hline Visio & $\begin{array}{l}\text { Create geodatabase } \\
\text { Create project data } \\
\text { Set datum } \\
\text { Create features }\end{array}$ \\
\hline ArcGIS Desktop 9.2 & $\begin{array}{l}\text { Create maps } \\
\text { Create data models } \\
\text { Run spatial analysis }\end{array}$ \\
\hline ArcMap & Clean imagery (smooth, filter, etc.) \\
\hline Other & Create code if necessary to create interface or analysis \\
\hline ERDAS IMAGINE 9.1 & Unzip or zip files \\
\hline Microsoft Visual Studio 2005 & $\begin{array}{l}\text { Use to read documents in Adobe Acrobat format } \\
\text { Export reports to Adobe Reader }\end{array}$ \\
\hline WinRAR & Adobe Reader 8
\end{tabular}

The software and applications used needed to be stored and have enough space to perform. Table 8 lists the minimum requirements for ArcGIS Desktop 9.2. One hardware component used was a Dell Precision M4300 laptop computer, and the system properties are listed in Table 9. The computer was used to implement software, run software, and run software applications. Another component of hardware was a server, which was provided by the Master of Science in Geographic Information Systems program at the University of Redlands. The server provided $1.36 \mathrm{~TB}$ of space on its network and the licensing of the listed software in Table 7.

Table 8. ArcGIS Desktop 9.2 Minimum Requirements (ESRI)

\begin{tabular}{|l|}
\hline MINIMUM REQUIREMENTS \\
\hline ArcGIS Desktop 9.2 \\
\hline Intel Pentium or Xeon computer \\
$1 \mathrm{GHz}$ processor \\
$512 \mathrm{MB}$ RAM \\
1 GB of free space \\
\hline
\end{tabular}


Table 9. Dell Precision M4300

\section{DELL PRECISION M4300}

Intel Core TM2 Duo

T7700@ $2.40 \mathrm{GHz}$

$2.9 \mathrm{GHz}$

2 GB of Ram

After the completion of the geodatabase and analysis, the geodatabase was moved to the Redlands Institute network. Security settings were set up to allow only the client and designated users to have write access to the geodatabase. Users who can access the Redlands Institute network will have read-only access to the geodatabase.

\subsection{User Interface Design}

The user interface design is shown in an example in Figure 13. The user interface design was based on user preferences. Most input of data was by workstation components such as keyboard and mouse. The data was displayed through the computer monitor. The data input and output was completed through ArcGIS 9.2 standard applications. The user interface to create and manage the geodatabase was in the ArcGIS Catalog and ArcMap software. The input data, output data, models, reports, and maps were to be stored in the Master of Science (MS) GIS server. The analysis was performed through the ArcGIS software and was stored in the MS GIS software. Table 10, provides a list of the input and output methods.

\section{Table 10. User Interface Methods}

\begin{tabular}{|l|l|}
\hline User Interface & Methods \\
\hline Input & $\bullet$ Mouse click \\
& $\bullet$ Keyboard \\
& $\bullet$ Scanning \\
& $\bullet$ Digitizing \\
\hline Output & - Reports \\
& $\bullet$ Features \\
& $\bullet$ Maps \\
& \\
\hline
\end{tabular}




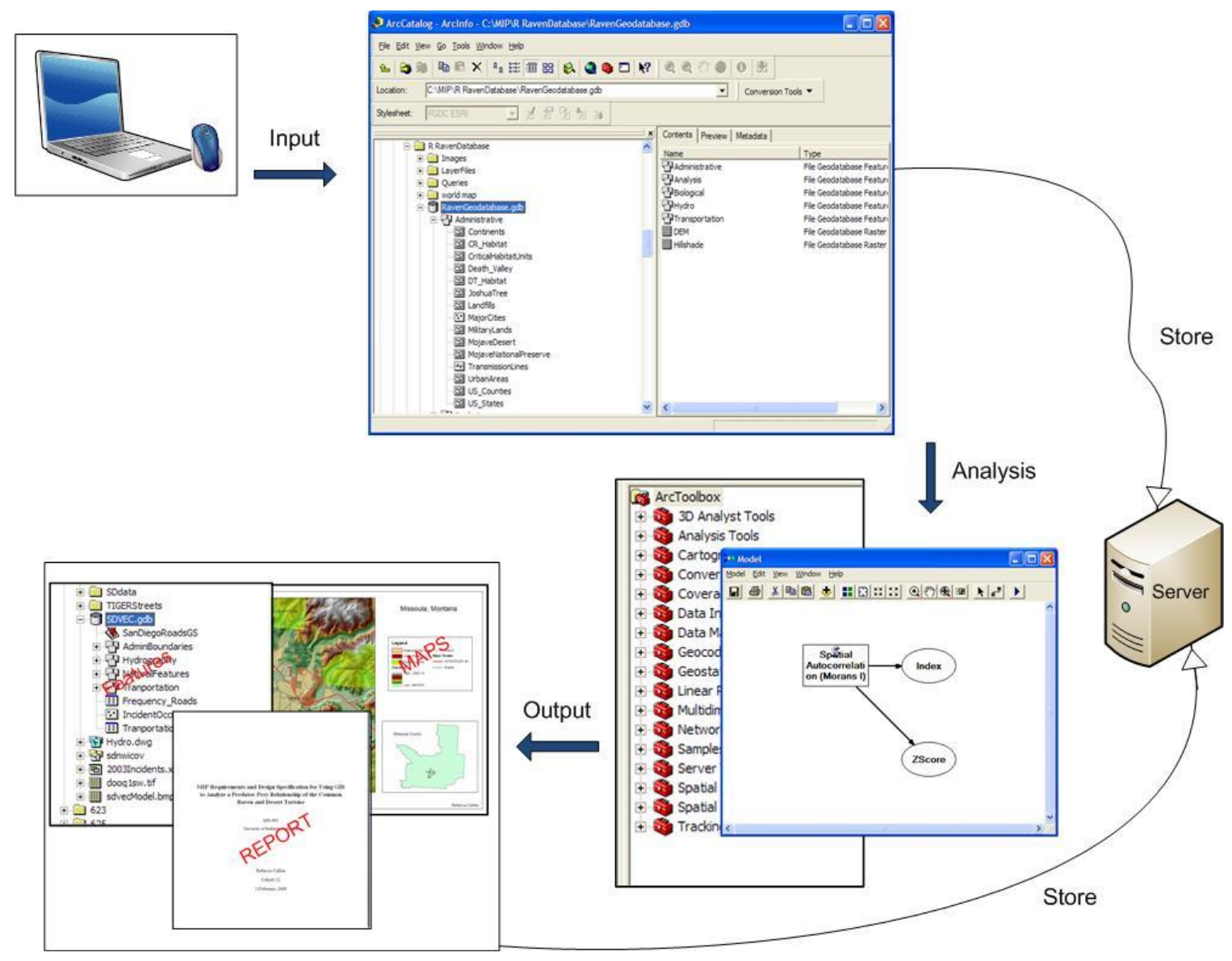

Figure 13. User Interface Design 



\section{Methodologies}

This chapter discusses the steps taken to create the geodatabase and deliverables for the client. The first step was data collection after which the database was designed and implemented. Next, analysis was performed on the nest data. Finally, a tutorial was created for the client to follow to learn how to use the geodatabase and analyze the data.

\subsection{Data Collection}

The raven nest data was provided by McIntyre. Data pertaining to military lands, Mojave National Preserve, Critical Habitat Units, roads, and cities was provided by the client; these datasets did not need any editing or maintenance.

The DEM that was provided by the Redlands Institute was clipped with the Clip tool found in the Analysis Tool in ArcToolbox. Then the Hillshade was created from the DEM by using the Hillshade tool in the Surface Analysis found on the Spatial Analysis toolbar. All the defaults were accepted and the Hillshade was saved in the Raven geodatabase.

The Mojave Ecoregion boundary was downloaded from the Mojave Desert Ecosystem program website. The file was in e 00 format. In ArcCatalog the Import from Interchange File found in the ArcView 8.x Tools was used to convert the e00 to coverage format. Then the polygon of the coverage was exported into the Administrative feature dataset in the Raven Geodatabase.

The National Park boundaries were downloaded from the National Park Service Data Store website. Death Valley and Joshua Tree were selected from the data set and then exported to the Administrative feature dataset in the Raven geodatabase. The client had provided the Mojave National Preserve shapefile.

The common raven habitat shapefile was provided by the Redlands Institute and created by California Department of Fish and Game's California Wildlife Habitat Relationship System. The data contained bird habitats and the common raven was selected and then exported into the Administrative feature dataset in the Raven geodatabase.

The desert tortoise habitat shapefile was also provided by the Redlands Institute and created by the California Department of Fish and Game's California Wildlife Habitat Relationship System. The data contained reptile habitats. The desert tortoise records were selected and exported into the Administrative feature dataset in the Raven geodatabase.

The nest data was provided in Excel spreadsheets and .dbf formats. The dataset that contained data from the years from 1990 to 2007 had to be cleaned. Dates were missing and other fields from the dataset. Meetings with the client were conducted to determine missing fields and what records needed to be eliminated from the dataset. This dataset was provided to McIntyre from Boarman. The data from 1990 to 2003 was selected and then exported to a new Excel spreadsheet. The data from McIntyre came in five Excel spreadsheets: 2004, 2005, 2006, 2007, and 2008. All of the datasets from McIntyre were combined. Then the exported records from 1990 to 2003 were added to the combined years of 2004 through 2007 (Sites table). Some of the attributes may not have information because they were not completed. For example, the some of the observations from 1997 did not have the type of substrate recorded. 
The Sites table had to be saved as a .csv (comma delimited) file. After saving the table, it was opened in ArcMap. The Add XY Data tool was used to create points based on the Northing and Easting fields. Then the Sites event was exported into a point feature class in the Biological feature dataset located in the Raven geodatabase.

When opened in ArcMap, some of the Sites attribute fields were converted into text, but they needed to be long integer. To change the fields to long integer, a new field was created with a new name and the properties were changed to long integer. Then the field calculator was used to populate the new field. Next the old field was deleted. After that, a new field was created with the same name as the old field. Finally, the field calculator was used again to populate the new field.

The data provided by County of San Bernardino Solid Waste Division were CAD files. The CAD data had to be exported into a polygon or polyline. The boundary of the landfill was selected from the attributes table, and then the CAD file was exported.

Some CAD files did not export to polygon correctly. For files that did not export correctly, the export to polyline technique application followed by the Feature class to Polygon tool in the ArcToolbox was used. When a CAD file was exported, the data frame properties were set to use the data frame coordinates so the file would change to the data frame projection. The data frame was projected in UTM Zone $11 \mathrm{~N}$ and the datum was set to NAD83. Still one CAD file was not complete. Staff at the county was contacted but they were not sure why the landfill boundary was not closed. This polyline was then edited with the Editor toolbar. The properties for the snapping tool were set to snap to the CAD lines. A line was drawn from one open end to the other open end to close the polyline. Then the Feature to Polygon tool was used to create a polygon.

After all the CAD files were exported to polygon, the polygons from Kern County, Los Angeles County, and Riverside County were merged to create a one polygon with all the landfills from the four counties. Then most of the fields were deleted because they were not necessary for this project. Some editing had to be done to add the name of the landfill to each object in the polygon. Next the landfill polygon was imported into the Administrative feature dataset in the Raven geodatabase.

\subsection{Database}

The database was created using ArcCatalog. Feature datasets were created with a projection of UTM Zone 11 North. Then the data was imported into each feature dataset.

Domains were created for the Sites feature class. The domains were created for the Pellets, Shells, Status, and Types attributes (Figure 14). The PelletsPresent domain provided a drop-down menu with the choices of Yes or No to indicate whether pellets were present at the site. The ShellsPresent domain provided a drop-down menu with the choices of Yes or No to indicate whether shells were present at the site. The Status domain provided a drop-down menu with the choices Nest Present or Nest Not Present at site location. For the Sites feature class, domains were created for the Sub_Type attribute which describes the substrate where the nest was located. The substrate options were Power Tower, Telephone Pole, Telephone Type Pole, Cliff, Joshua tree, and Other. Domains were created to make the process easier when a user adds new data to the database. All the domains were coded values and text. 


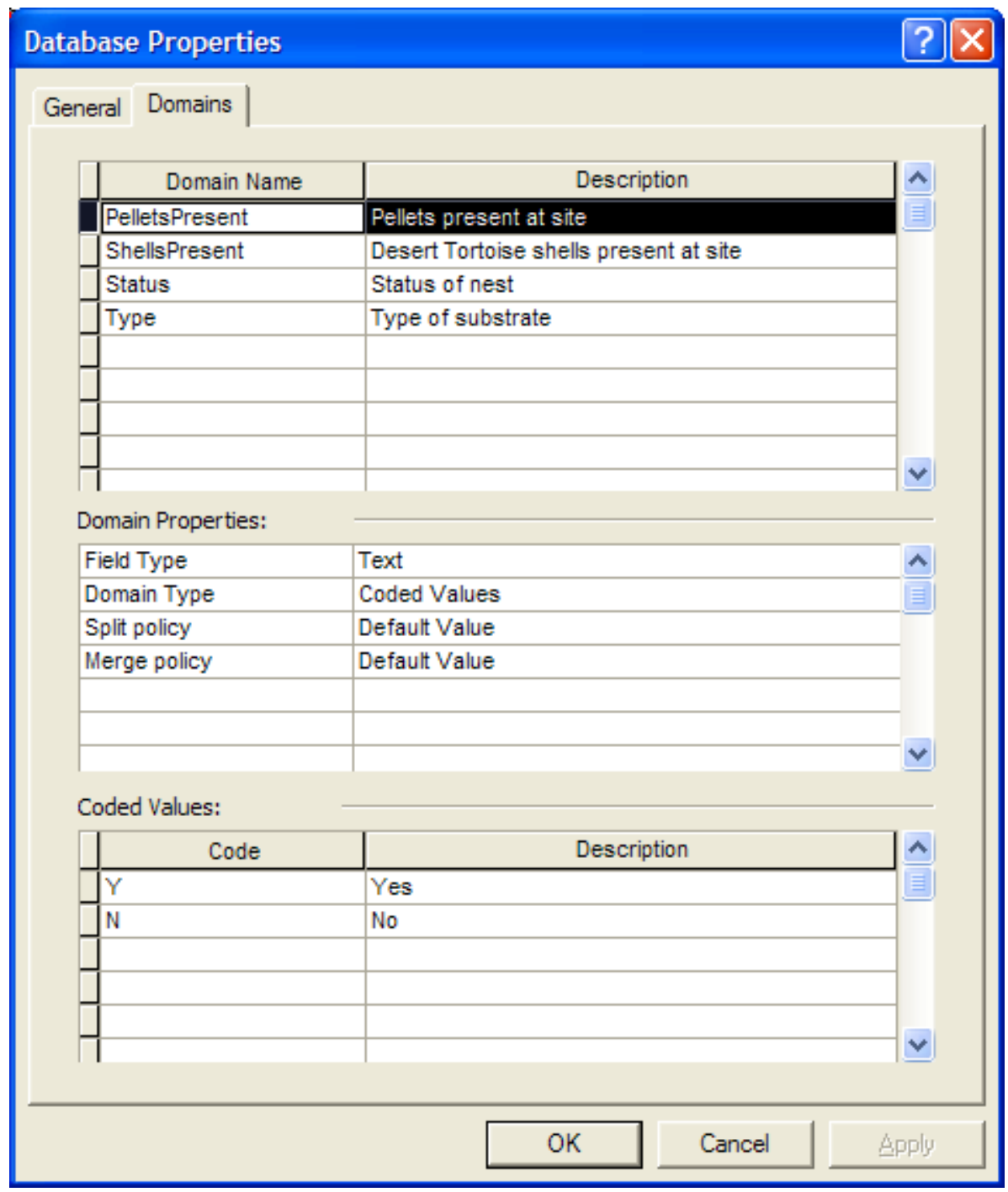

\section{Figure 14. Geodatabase Domains}

The lakes and reservoirs were combined into one feature class from USGS. The lakes were selected and then exported into a polygon. The same process was repeated to extract the reservoirs. Both of these features were imported into the Hydro feature dataset in the Raven database.

The other features, such as rivers, and roads, were placed in feature datasets. The feature datasets were created in ArcCatalog. Figure 15 displays the feature datasets, feature classes, table, DEM, and Hillshade. 


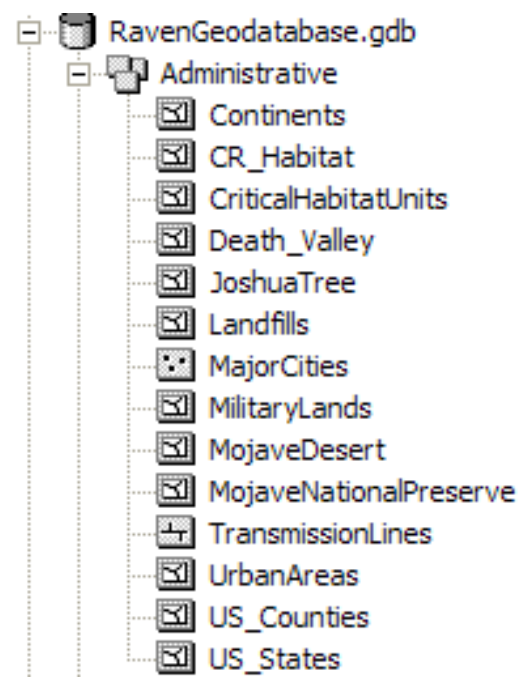

$$
\begin{aligned}
& \text { Analysis } \\
& \text { - Thiological } \\
& \because \text { Sites } \\
& \text {-7 } \\
& \text { 제 Lakes } \\
& \text { 지 Reservoir } \\
& \text { It Rivers } \\
& \text { - T Transportation } \\
& \text { It Highways } \\
& +\ldots \text { DEM } \\
& + \text { Hillshade }
\end{aligned}
$$

\section{Figure 15. Raven geodatabase}

\subsection{Analysis}

The common raven data used to analyze raven predation was too dispersed to perform any spatial analysis such as correlation. The objective of this project was to see if there was correlation between sites with shells and sites with no shells pertaining to the location of anthropogenic and natural features. Out of 1,859 records, only 107 had shells. Out of the 107 observations, only 93 were visited once. So with two different population sizes, the analysis would not be significant (Ren, personal communication, June 25 , 2008). Therefore, visual analysis was performed with the latest data. This visualization was a continuation of McIntyre's previous maps of hot spot locations.

SQL queries were created for each year. They were saved for the client to be able to load the query without having to type the same query for queries, analysis, and symbolization. The queries were performed for each year through the Select by Attributes (Figure 16). 


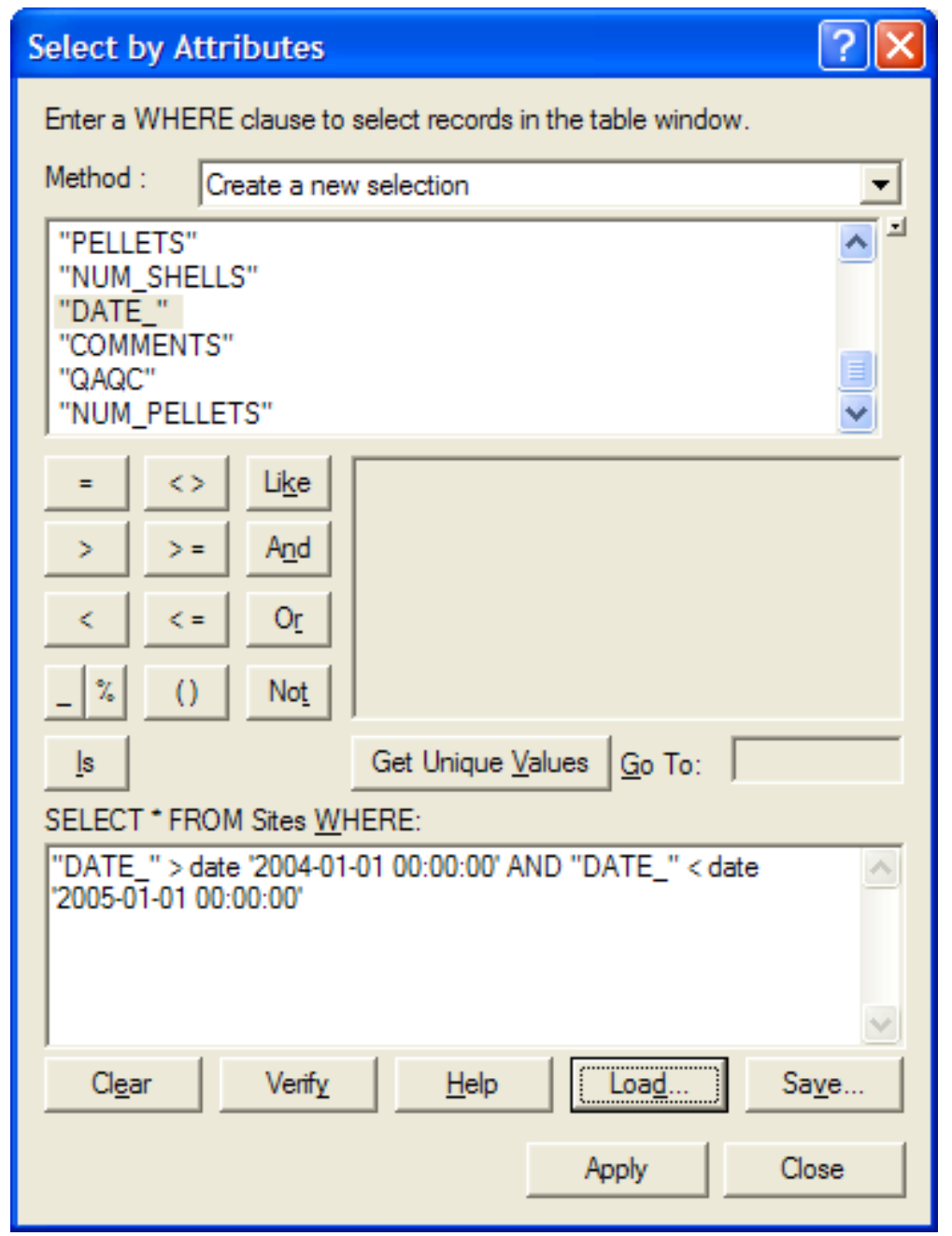

\section{Figure 16. SQL Query}

After the queries were executed, a new layer within the map was created with the Create Layer with Selected Features under the Selection tool. This created a layer with the selected data from the Sites feature class. Queries were performed for each year from 2004 to 2008. Then, with the new layer, the feature was symbolized based on the number of shells found at each site (Figure 17). At this point, the layer was saved as a layer file so the client could import the same symbology into another map. 


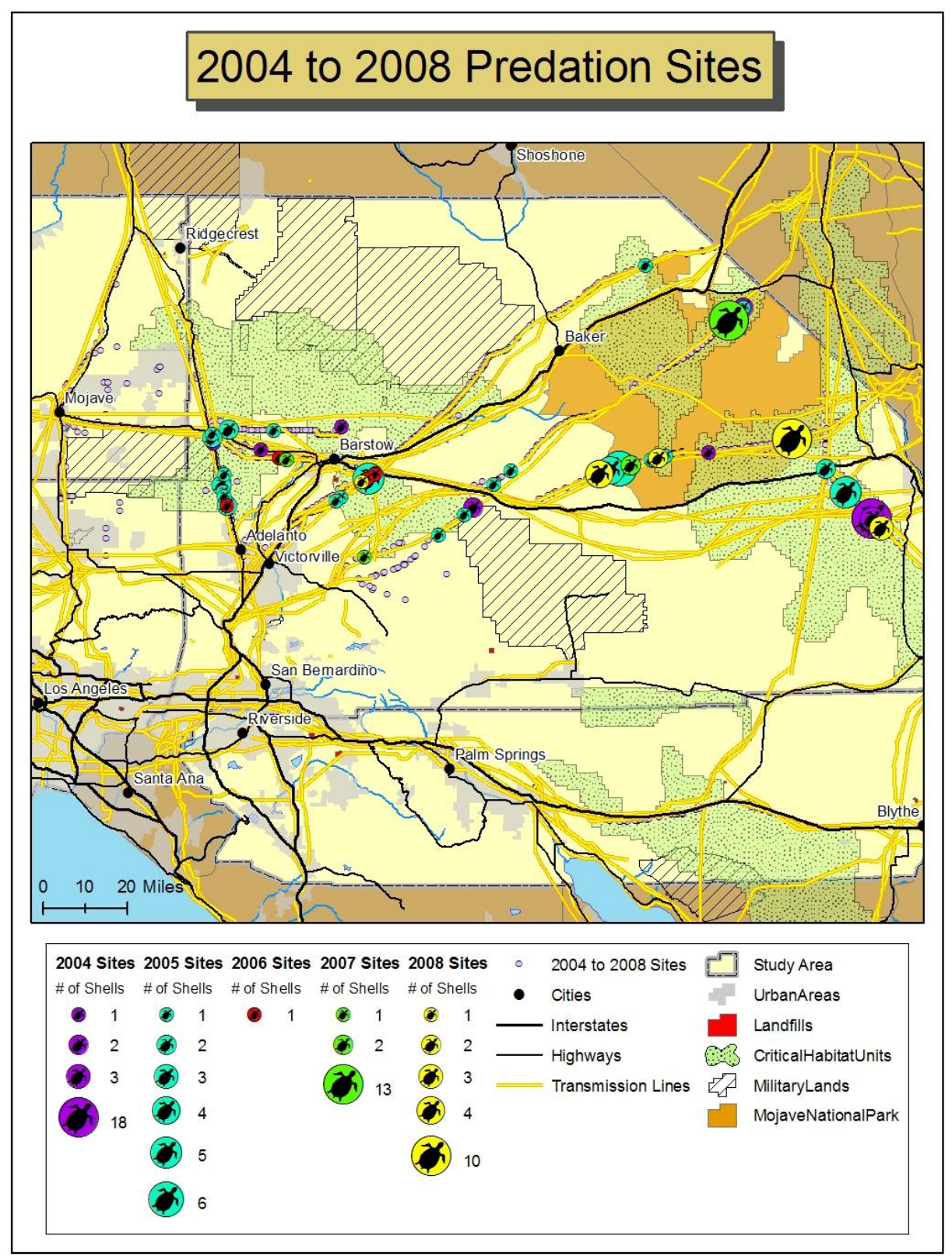

\section{Figure 17. 2004-2008 Predation Sites}

A query was created to select common raven observations for each year. The queries were performed by selecting a year and selecting the common raven as the species. A selection layer was created in the map. The layer was symbolized by the number of shells found (Figure 18). 


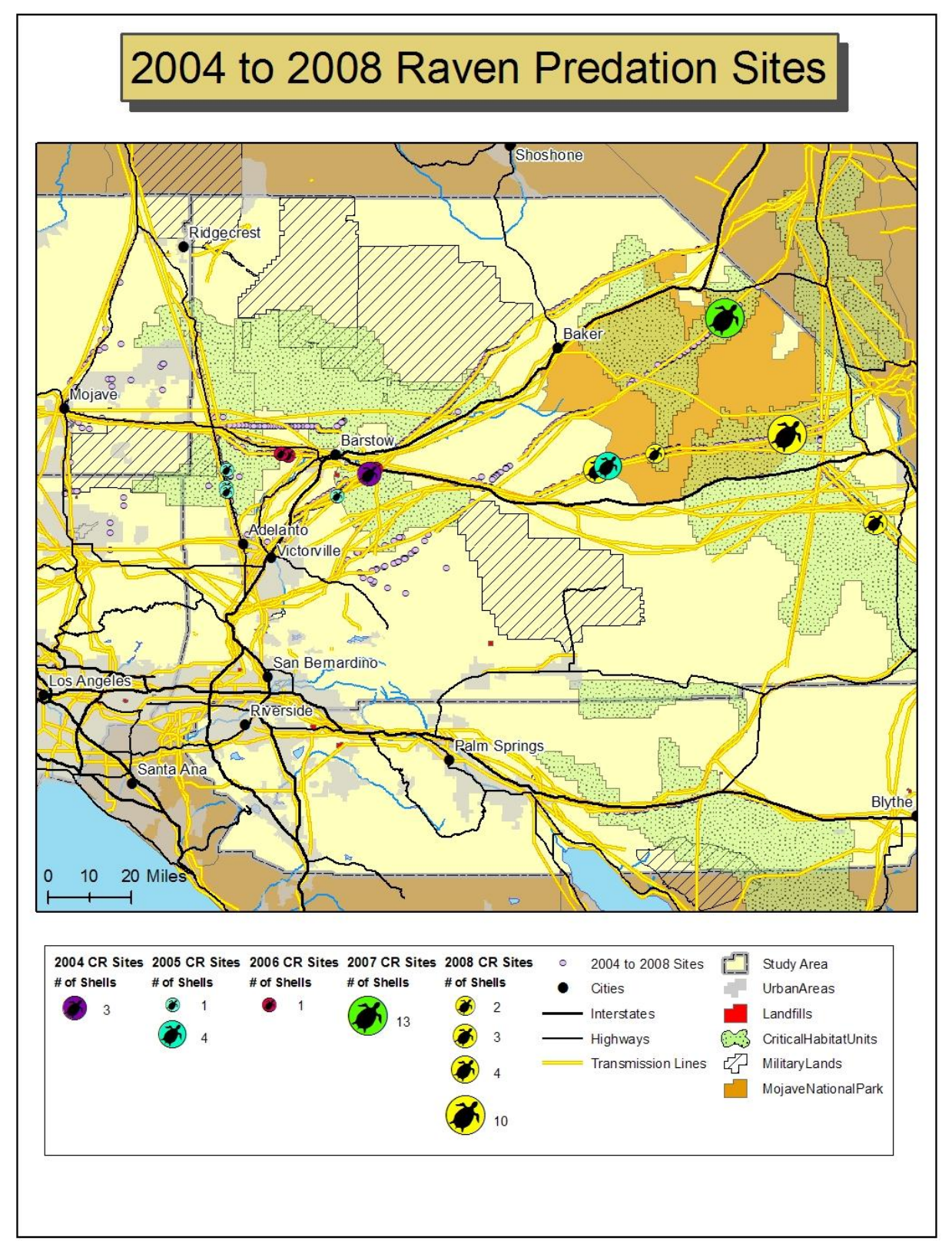

Figure 18. Common Raven Predation from 2004 to 2008

Next, a query was created to select common raven sites found at power towers. This query was used to analyze nests found on power towers to compare nests found on natural features. The same type of query was used to select the other substrates of Telephone Poles, Telephone Type Poles, Cliffs, Joshua trees, and Other. Then the number of shells found at each substrate was queried as follows: This query "NUM_SHELLS" > 0 AND "SUB" = 'PT' was used to find the number of power tower raven sites with predation. The Statistics tool was used on the NUM_Shells attribute column to display the sum of number of the shells found (Figure19). Figure 20 shows the total of shells for all observations of the Sites feature class. 


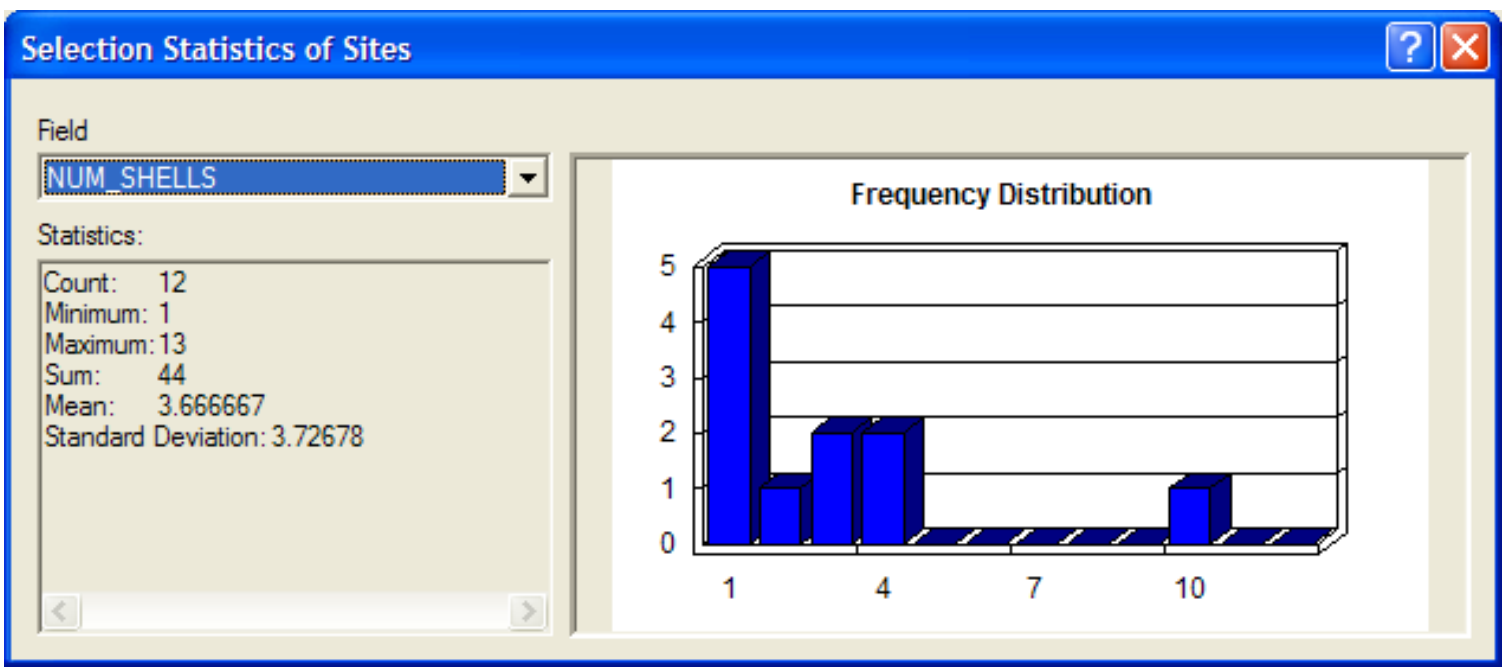

Figure 19. Statistics of query selection of Raven Predation under Power Towers for 2004 to 2008.

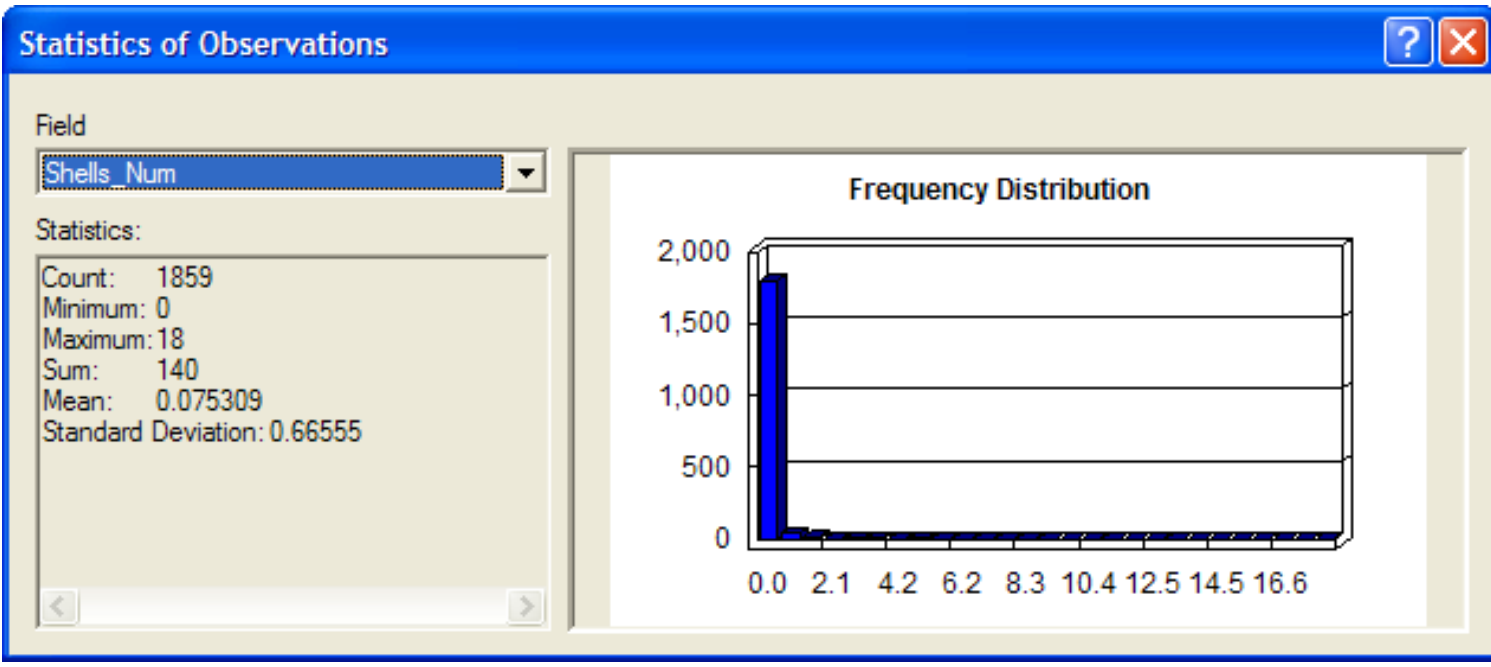

\section{Figure 20. Statistics of Number of Shells for Sites feature Class}

There were not many records for the other species observed, so these species were combined into a category of Other. There were many records for the common raven, the red-tailed hawk, and unknown species of birds, so they were queried and a selection was created for each species type. The same process was used to query the red-tailed hawk, unknown birds, and other species.

For the Other selection the NOT function was used. This query used the function NOT to avoid selecting the red-tailed hawk, common raven, and unknown species data.

$$
\begin{aligned}
& \text { NOT "SPECIES" = 'CR' AND NOT "SPECIES" = 'RTH' } \\
& \text { AND NOT "SPECIES" = 'UNK' }
\end{aligned}
$$

This approach selected other species' nests found during the 2004-2008 period. Queries were created to select Unknown species and a selection layer was created. The same was created for Other species. 


\subsection{Maps}

Maps were made of the nest locations. McIntyre had previous maps from 2004 to 2007. New maps were created with the 2008 data. Symbology was created for each layer, and then saved as a layer file for future use. The layer file preserves the symbology so users do not have change the symbology every time they open the map. The nest layers, segregated by year, were created from the queries in the section above.

Maps were created for a study overview (Figure 6), predation sites over the past five years (Figure 17), common raven predation over the past five years (Figure 18), and predation for the year 2008 (Figure 21).

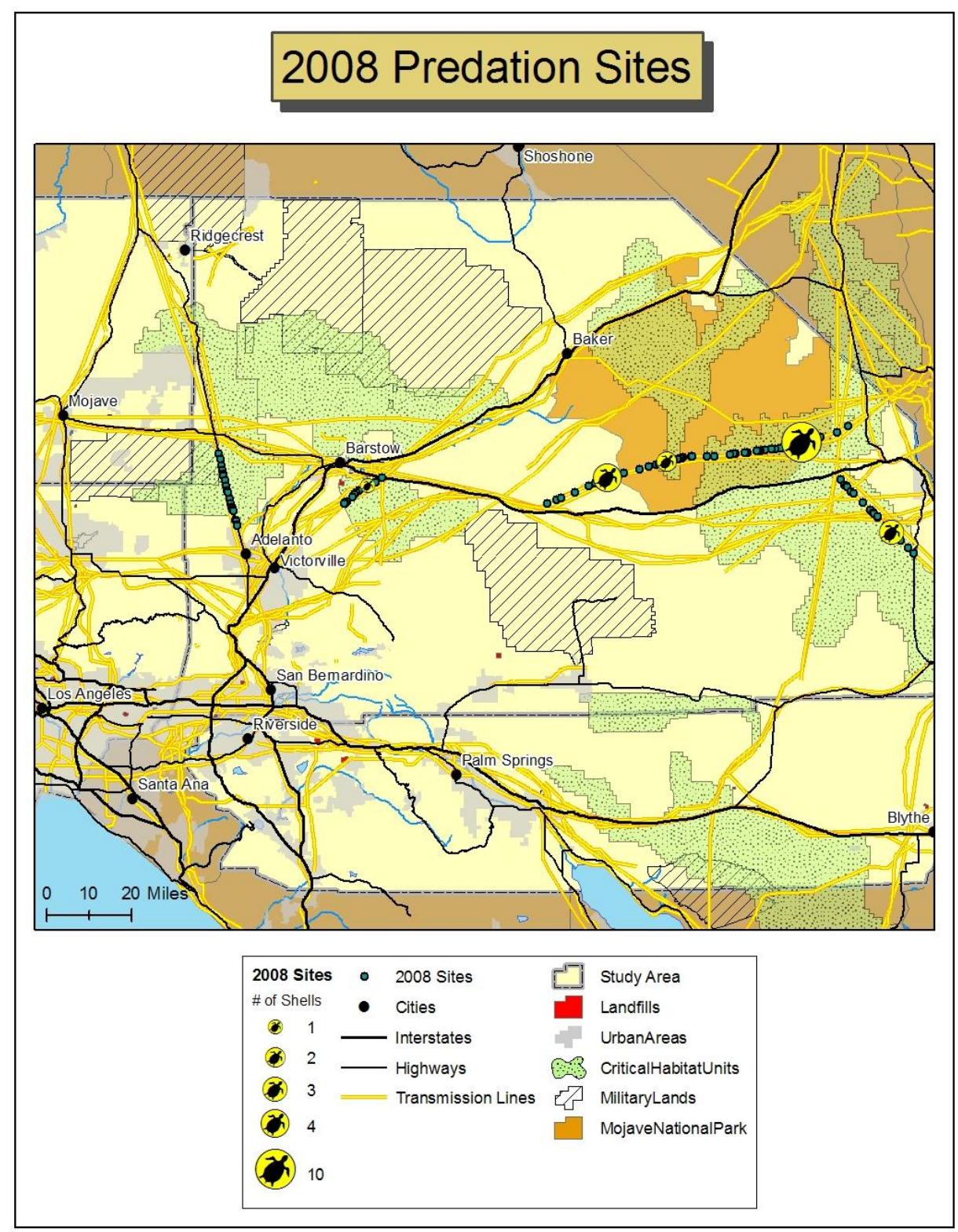

Figure 21. Predation Found for 2008 


\subsection{Test}

A GIS tutorial was created for the client (detailed in Appendix A). The tutorial was developed for a user with no GIS experience. The instructions include steps on how to access data, edit data, query, and symbolize. The tutorial used the Raven geodatabase. Using the tutorial, the client tested the geodatabase. The test required the client to follow the tutorial and make comments if steps were confusing. These comments were then taken and changes were made to the tutorial. The tutorial was made for the client to be able to use the geodatabase without the help of a GIS specialist, and it provides very basic instructions to allow the user to be able to run queries. 


\section{Discussion}

This section discusses the analysis outcomes and the limitations of the data.

\subsection{Analysis}

The visual analysis with maps reveals areas that have had reoccurring predation, as shown in Figure 17. Figure 18 shows nests that were known common raven nests. In the observations, there are many nests that are for unknown species. Where there were no direct signs of a common raven inhabiting a nest, the nest was marked as unknown. Figure 14 shows the common raven nests that did have predation. Out of the observations for the years 2004-2008, there were 219 known common raven nests out of the 1,331 sites observed, and out of the 1,331 sites, 993 observations were unknown species. There were 64 predation sites out of the 1,331 observations and 44 were unknown species. Of the remaining 19 sites, 14 were known to be common raven nests. Table 11 displays the summary of the number of nests found for the common raven, red-tailed hawk, other and unknown species.

Ninety-six percent of all nests found were on anthropogenic features; however, the samples were collected on the basis of seeking power towers and structures known to be used for a common ravens' nests. The sampling technique for observing nests was not random; however, the observations were based upon accessibility. The data content and sampling technique made it difficult to statistically analyze the data. Research is recommended to find an appropriate method to statistically analyze the data. 
Table 11. Summary Table

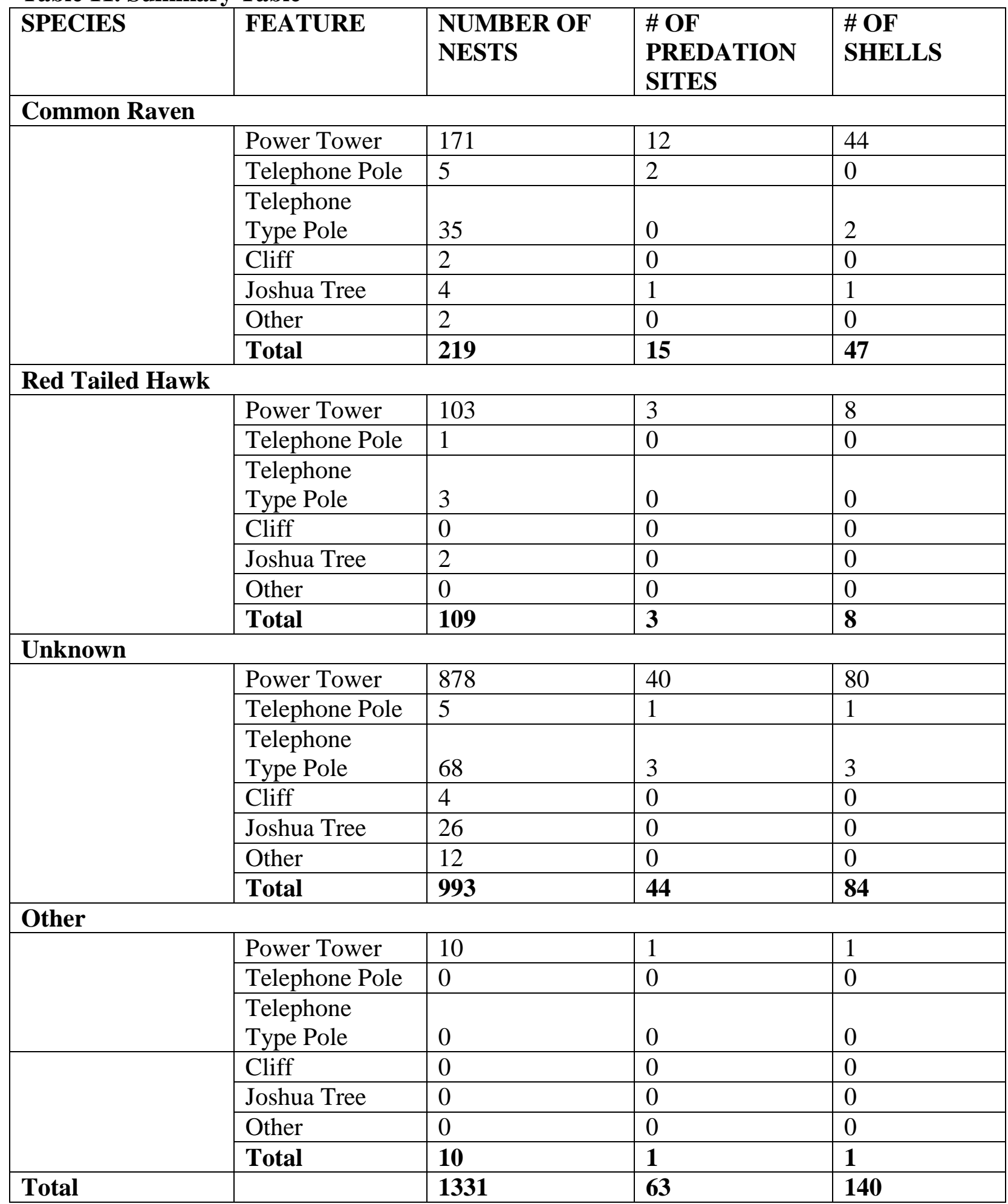

The relevance of the visual analysis is that the areas with known predation can be observed again for the Environmental Assessment to Implement a Desert Tortoise Recovery Plan Task: Reduce the Common Raven Predation on the Desert Tortoise (EA) 
(U.S. Fish and Wildlife, 2008). Researchers can observe the sites over a more frequent period to determine if one raven is a repeat offender preying on desert tortoises. For example, in 2008, one site had ten tortoise shells under a common raven nest. It is not known if there is one raven or two inhabiting the nest. This data provides known locations of nest where predation on the desert tortoise has occurred which allows researchers to observe these areas more closely and determine if the alternative method of removal action is necessary under the EA for raven management.

\subsection{Limitations}

There are limitations to the nest data. The nest data provided by the client was edited by combining Excel spreadsheets and inputting data into missing fields; however, there are still discrepancies in the dataset. Some of the records with the same MasterID had the same substrate but the descriptions were different. Also, many fields in this project are empty depending on the accuracy and amount of information provided by the person who recorded the observation. Therefore, the data could be biased if all the observers did not follow the same techniques. Some of the observations taken over the five years may have been of the same site, but with the collection techniques used to collect data, it was unknown whether Dr. Wendy McIntyre had visited some of the sites before. It is recommended that the hard-copy records and database be compared and evaluated and make changes to the database as necessary. Records were carefully observed in the development of the tables, but errors may have occurred due to the time constraint and lack of knowledge of the data collected. The most frequently used description was chosen for sites where there were more than two observations. Therefore, some of the data may not accurately reflect the type of substrate. 



\section{Summary}

The objectives of this project were to build a functional geodatabase and be able to make inferences on the data provided by the client. The data was organized into feature datasets in a file geodatabase for the client and query operations were accomplished. Based upon queries the common raven data and predation on the desert tortoise can be analyzed visually. The visual analysis provided spatial information of where predation was occurring. The knowledge of where predation is occurring is very useful for U.S. Fish and Wildlife Service and the Environmental Assessment to Implement a Desert Tortoise Recovery Plan Task: Reduce the Common Raven Predation on the Desert Tortoise (EA) (U.S. Fish and Wildlife Service, 2008). The objective of performing statistical analysis was not completed but the data is organized to be able to use for future analysis such as statistical applications. The project was beneficial in its being an opportunity for gaining knowledge and experience with GIS and to build an efficient geodatabase. The project was a step into personal future endeavors in GIS.

\subsection{More Data}

Future work could include incorporating more data into the database. Not included in the geodatabase was agriculture - food and water sources provided by humans for the common raven. Irrigation canals would also be another type of object to consider in analysis of common raven habitat. Rest stops are another anthropogenic feature that is a food subsidy for the common raven. As such, rest stops could be included as well to illustrate the proximity of rest stops to nest locations.

\subsection{Design and Custom Interface}

The conceptual design organized the nest data into a normalized database. The separation of the data into a normalized database would require removing duplicate MasterID records for the Sites feature class. The record kept should be the most recent UTM coordinates for the Site if there is more than one observation. This decision was made after a discussion with McIntyre. Then a composite relationship class would be created between the Sites feature class and Observations table. The project scope was not to customize, but programming would be required to symbolize a join for a one-to-many relationship. A workaround without customizing would be redundant but it would not have multiple points stacked on top of each other as they are now. Ideally, tables could be created for each year. A composite relationship of one-to-one could be created between observations and each year. For example, the Observations table would be related to the Observations 2004 table (Figure 22).

Regardless of the design of the database, a user interface could be created. An application could be created wherein a user could enter all the data on one user interface. Programming would be required for the interface to create new sites points and observations. This would make it easier for a user with little GIS experience. The user could input the data in the field with the interface and would not have to know how to use the tools in ArcMap. The interface could input the data and the user would not have to start an editing process, open tables, and so forth. 


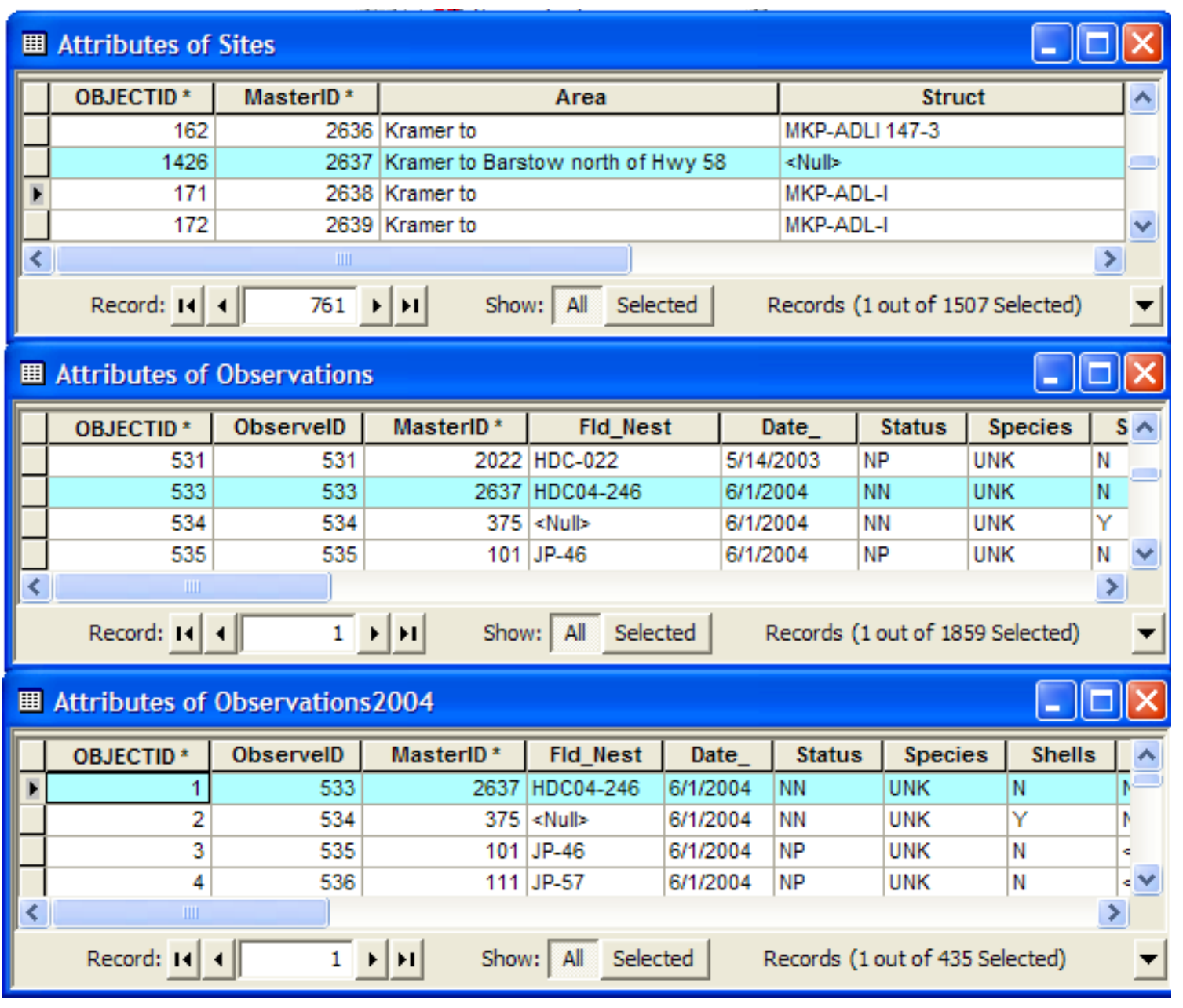

\section{Figure 22. Composite Relationships}

A composite relationship class would help with data management. A composite relationship allows for a cascade delete (ESRI, 2006b). This technique would require extra tables that contain the same information as the Observations table using a cascade delete, but would allow for a one-to-one join between the Sites feature class and the Year table such as Observations 2004. This design would also have to create a new table for the years thereafter when new data is added to the Observations table; however, customizing an application to symbolize a one-to-many join would be the most efficient for the database. It would require less maintenance if there were only two tables to update instead of multiple tables.

\subsection{Mobile tools}

Creating a design to implement mobile tools would be beneficial in future data collection. Using mobile software such as ArcPad could be useful for the client. A database design would need to be organized to handle data versioning and implementing new data from a mobile device to the database. In the past, the data had been collected using paper and then would be input into Excel spreadsheets. Creating a design to allow for input of data from mobile devices would make the database easier to update and maintain. 


\subsection{Conclusion}

The data was organized into a database that the client will be able to use for future analysis and data collection. The data presented helps users visualize areas with reoccurring predation based on the observations collected in the past five years. Data collected previous to 2004 was not analyzed because the client specified the need for analysis of the data collected from 2004 to 2008. More research could be conducted to find a method suitable for spatial analysis that would bring to find a more statistically sound results. The sites of known reoccurring predation could be observed regularly.

The original scope of the project was to correlate the nest locations; however, this was eliminated from the project due to the data content. More research in different techniques on correlation would be useful. It is important to find out whether there is correlation to have a better understanding of the common raven nest locations. For example, is a nest location based on the accessibility to anthropogenic features or does it not matter at all. Based on prior studies, it is known that common ravens feed off of human subsidies. But what about the nests with predation on the desert tortoise? Is there more or less predation around nests near anthropogenic food sources?

Reducing the common raven population in the desert tortoise critical habitat units is important because it could help the desert tortoise population recover. The sites that were observed help researchers know where predation is occurring in small sections of the Mojave Desert. 



\section{References}

Anderson, M. C., Watts, J. M., Freilich, J. E., Yool, S. R., Wakefield, G. I., McCauley, J. F., et al. (2000). Regression-tree modeling of desert tortoise habitat in the central Mojave Desert. Ecological Applications, 11 (6), 890-900.

Boarman, W. I. (1993). When a Native Predator Becomes a Pest: A Case Study. Paper presented at the Conservation and Resource Management.

Boarman, W. I. (1997). Predation on Turtles and Tortoises by a "Subsidized Predator". Paper presented at the Conservation, Restoration, and Management of Tortoises and Turtles - An International Conference.

Boarman, W. I. (2001). Desert Tortoise Gopherus agassizzii. Report to the West Mojave Planning Agency. o. Document Number

Boarman, W. I. (2003). Managing a Subsidized Predator Population: Reducing Common Raven Predation on Desert Tortoises. Environmental Management, 32(2), 205217.

Egenhofer, M. J., Frank, A. U., \& Hudson, D. L. (1997). The Design of Spatial Information Systems Part 2: Knowledge Representation.

ESRI. ArcView Evaluation Software - Frequently Asked Questions. Retrieved February 24, 2008 from http://www.esri.com/software/arcgis/arcview/eval/evalcdfaqs.html\#sysreqs.

ESRI. (2006a). About joining and relating tables. ArcGIS Desktop Help, from http://webhelp.esri.com/arcgisdesktop/9.2/index.cfm?id=2754\&pid=2745\&topicn ame=About_joining_and_relating_tables

ESRI. (2006b). Relationship Class Properties. ArcGIS Desktop Help, from http://webhelp.esri.com/arcgisdesktop/9.2/index.cfm?id=2118\&pid=2114\&topicn ame=Relationship_class_properties

ESRI. (2006c). Relationship Class Properties. ArcGIS Desktop Help, from http://webhelp.esri.com/arcgisdesktop/9.2/index.cfm?id=2118\&pid=2114\&topicn ame=Relationship_class_properties

Hogle, I. B., Viers, J. H., \& Quinn, J. F. (2007). Habitat Restoration Monitoring and Assessment: A Personal Geodatabase Design. Paper presented at the ESRI International User Conference 2007. Retrieved August 9, 2008, from http://gis.esri.com/library/userconf/proc07/papers/papers/pap_1425.pdf

Kristan, W. B., III, \& Boarman, W. I. (2003). Spatial Pattern of Risk of Common Raven Predation on Desert Tortoises. Ecology, 84(9), 2432-2443.

Lang, L. (1998). Endangered species. In Managing Natural Resources with GIS. Redlands: Environmental Systems Research Institute, Inc.

McIntyre, B.M. (2007, October 25). Using GIS to Quantify the Threat and Status of the Common Raven to Desert Tortoise at Fort Irwin and National Training Center. Lecture presented at Wendy McIntyre's Faculty Club Forum, University of Redlands 
McIntyre, B. M., Leuteritz, T. E. J., and Kumler, M. P. (submitted). Using GIS to Quantify the Anthropogenic-Induced Raven Threat to Desert Tortoise.

Mukerjee, R. (1930). The Regional Balance of Man. The American Journal of Sociology, 36(3), 455-460.

U.S. Fish and Wildlife Service. (November 15, 2007). Desert Tortoise Recovery Office. Retrieved July 7, 2008, from http://www.fws.gov/nevada/desert_tortoise/dt_life.html

U.S. Fish and Wildlife Service. (2008). Environmental Assessment to Implement a Desert Tortoise Recovery Plan Task: Reduce Common Raven Predation on the Desert Tortoise. Retrieved May 15, 2008. from http://www.fws.gov/ventura/newsroom/newsreleases/2007/0405_draftea_ravenmanagement.html.

Viers, J. H., Hogle, I. B., DiPietro, D., Arora, S., Gubaydullin, M., \& Quinn, J. F. (2005). Geodatabase Application for Invasive Plant Tracking and Coordinated Habitat Restoration. Paper presented at the ESRI User Conference 2005. from http://gis.esri.com/library/userconf/proc05/papers/pap1416.pdf 
Appendix A-Raven Geodatabase Tutorial 


\section{Appendix A-Raven Geodatabase Tutorial}

This tutorial shows how to add, query, and edit data. The audience for this tutorial is the user with little or no experience with ArcMap 9.2. All images were taken from ArcMap 9.2.

Step 1: Open ArcMap from the Start Menu.

Step 2: Make sure the radio button for "A new empty map" is highlighted, and then click OK.

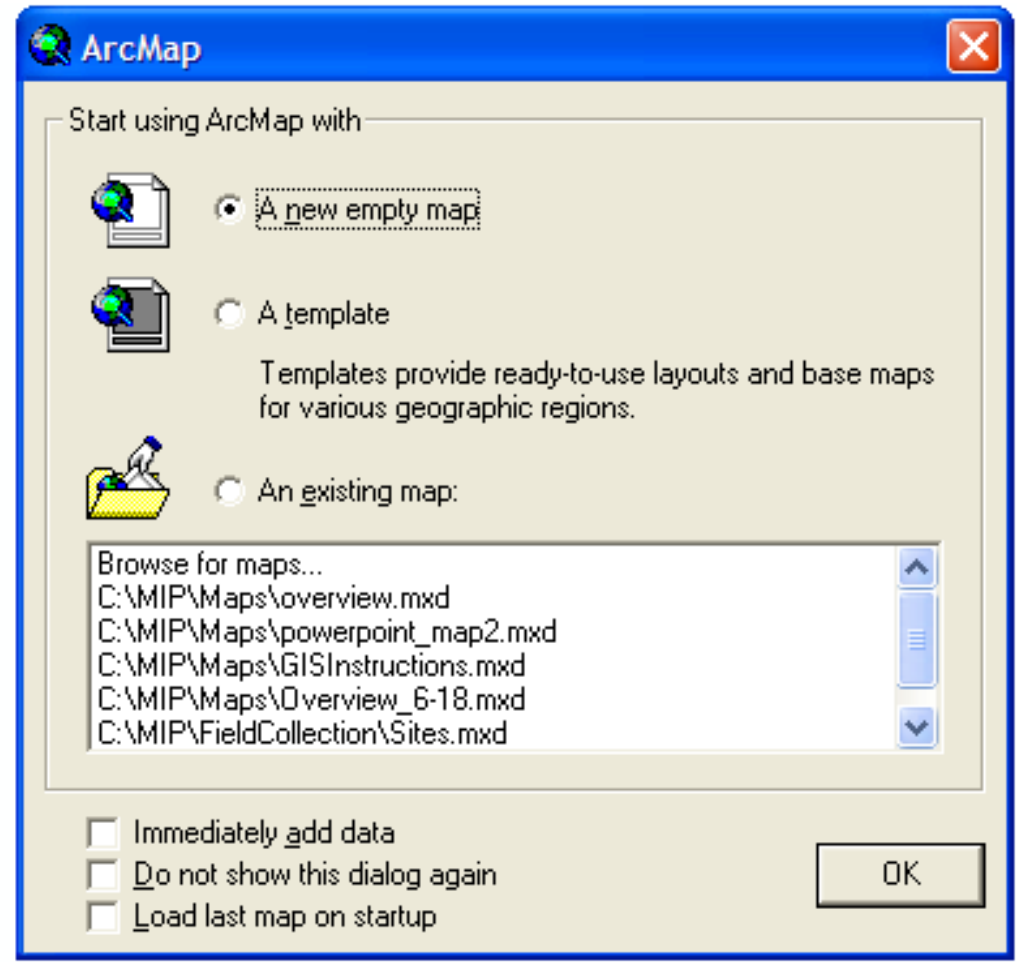

Step 3: Click View located on the menu in the upper left corner of the screen. Then scroll down and select Toolbars. Make sure the Main Menu, Editor, and Standard toolbars are checked. If they do not have checkmarks, click on Main Menu and Editor. This will bring up the Main Menu and Editor toolbars.

Step 4: Save the map under a unique name that will identify the purpose of the map. Click on File, then choose Save. Browse to the desired location for the map.

Step 5: Click the Add Data button. Browse to the folder containing the RavenGeodatabase.

(R:\Projects\DTP\Projects\RavenResearcRavenDatabase\RavenGeodatabase) 


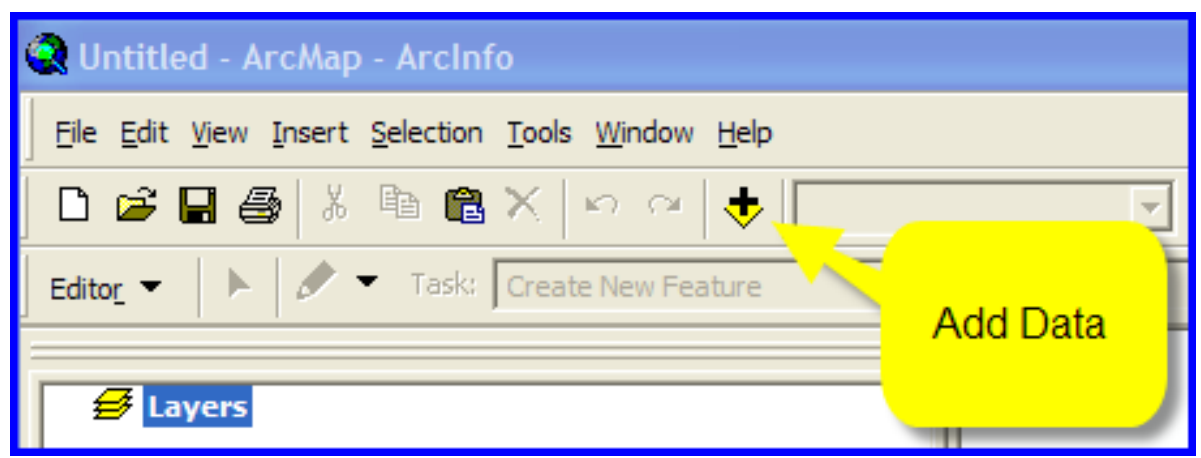

Double-click RavenGeodatabase to open the geodatabase. Then double-click on the feature dataset called Biological. This will open the feature dataset. Then choose the Sites feature class and click Add.

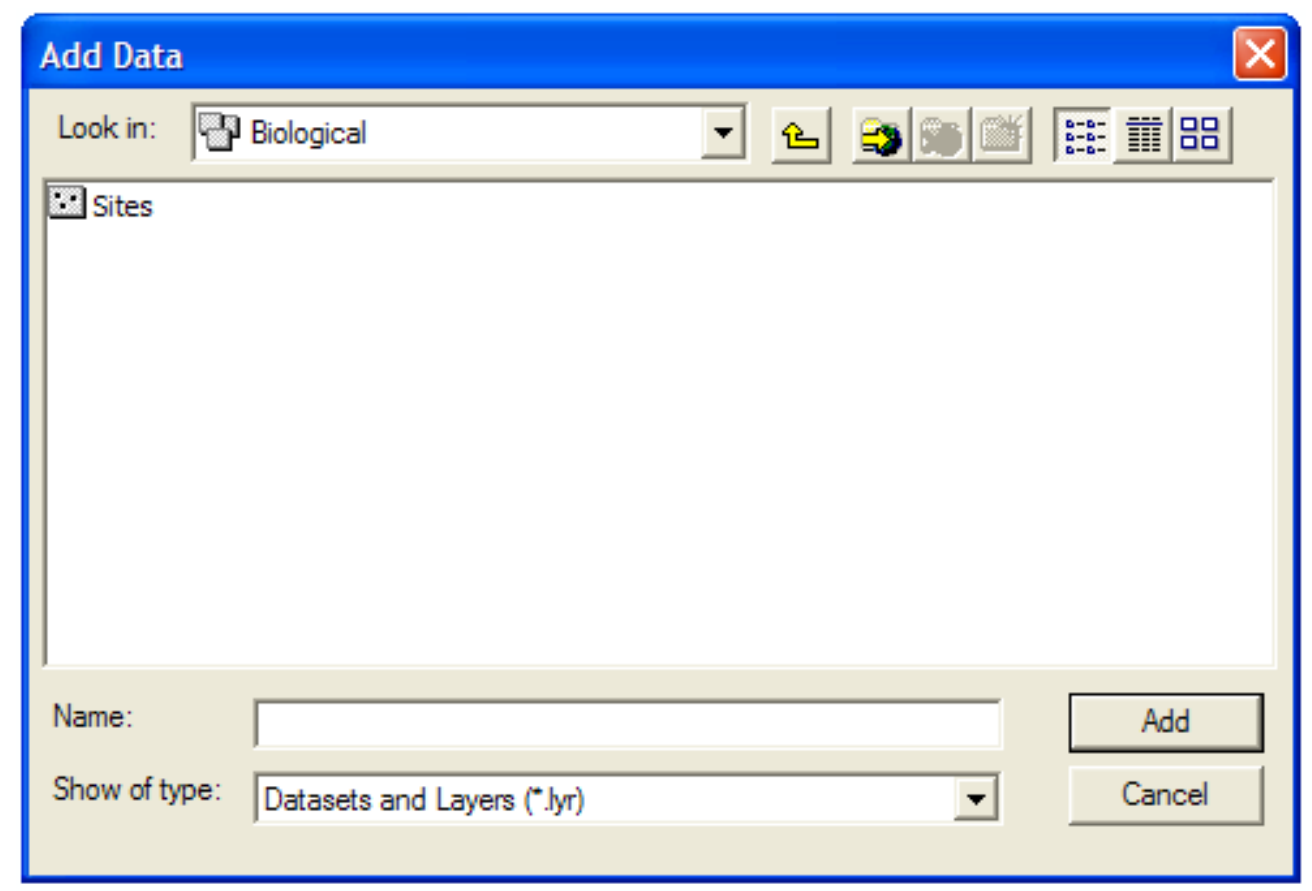

Depending on the settings of ArcMap, you may have to zoom in closer to the feature. If this is the case, select the magnifying glass on the Standard toolbar.

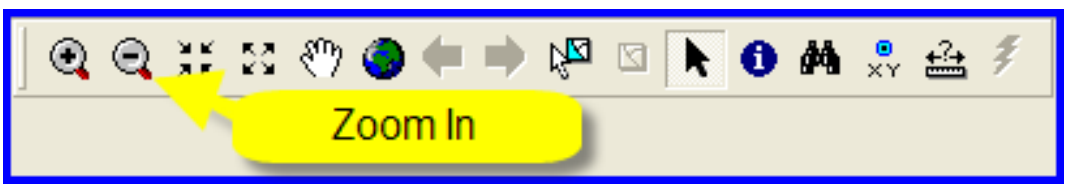

With the Zoom In tool, you can hold down the left button of the mouse and drag the cursor over the area. When you let go, the data will be zoomed in to the extent of the box drawn around the area. Alternatively you can click once and the tool will zoom in as well, but not to the same extent as drawing a box around the area of interest. Also, when you hover the mouse over a tool, a pop-up menu will appear with a description of what the tool does.

Step 6: Right-click the Sites feature class on the Table of Contents menu. 


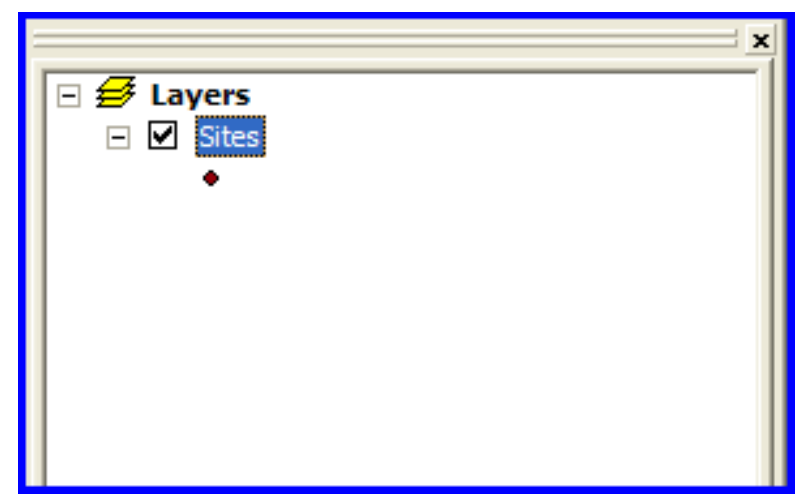

Then choose Open Attribute Table. This will open the attribute table for the Sites feature class.

Step 7: Click the Options button in the Observations table. Then choose Select by Attributes. This will open the query box. The query is in SQL.

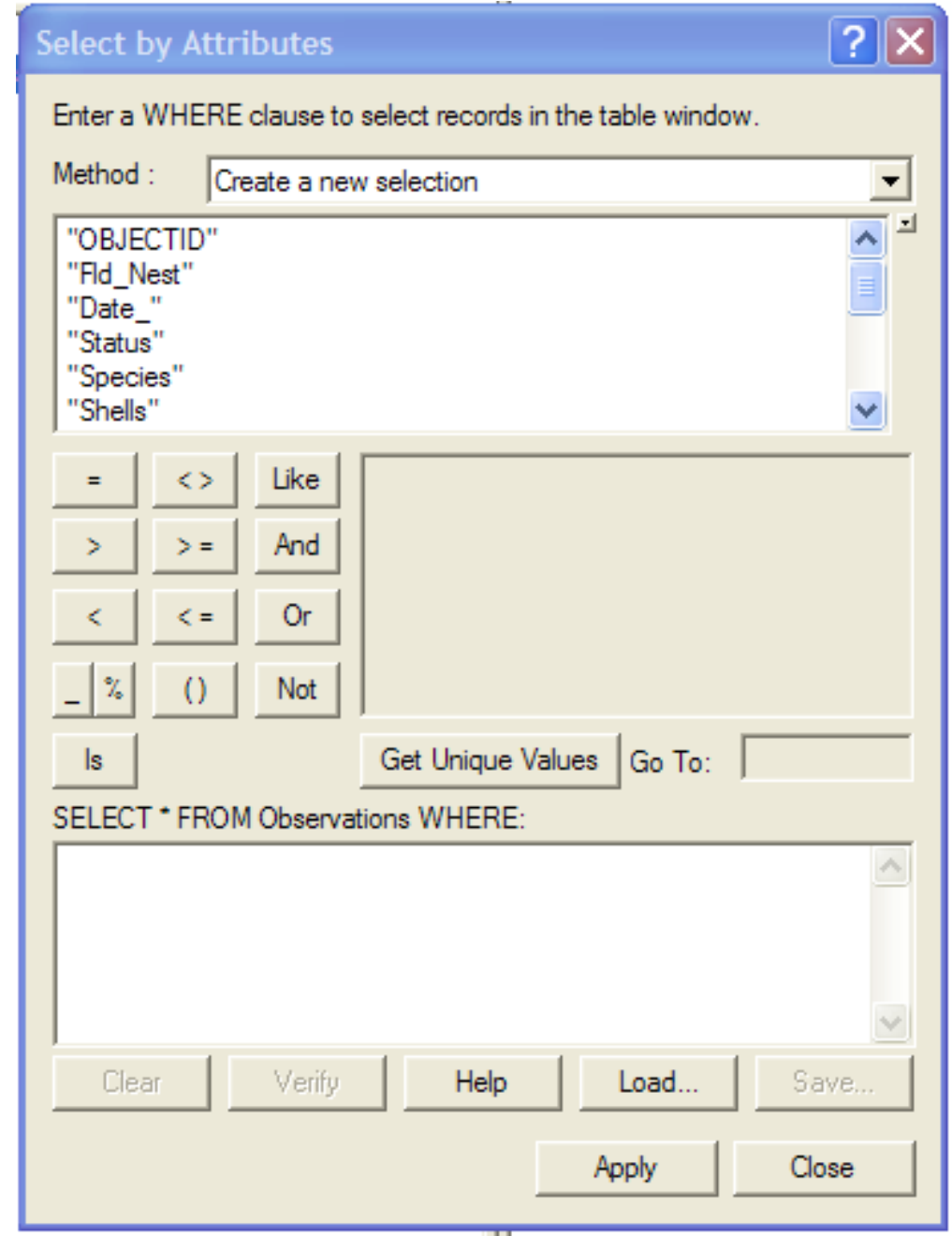

To query by Desert Tortoise shells, double-click "Shells" on the menu. This will designate how to select the records you want. Then click the $=$ button on the query box. Next click the Get Unique Values button. This will bring up the attributes under this 
field. Then double-click ' $Y$ ' - Yes. This will complete the SQL query to select all records that indicate the presence of Shells. The graphic below shows what the SQL statement should look like.

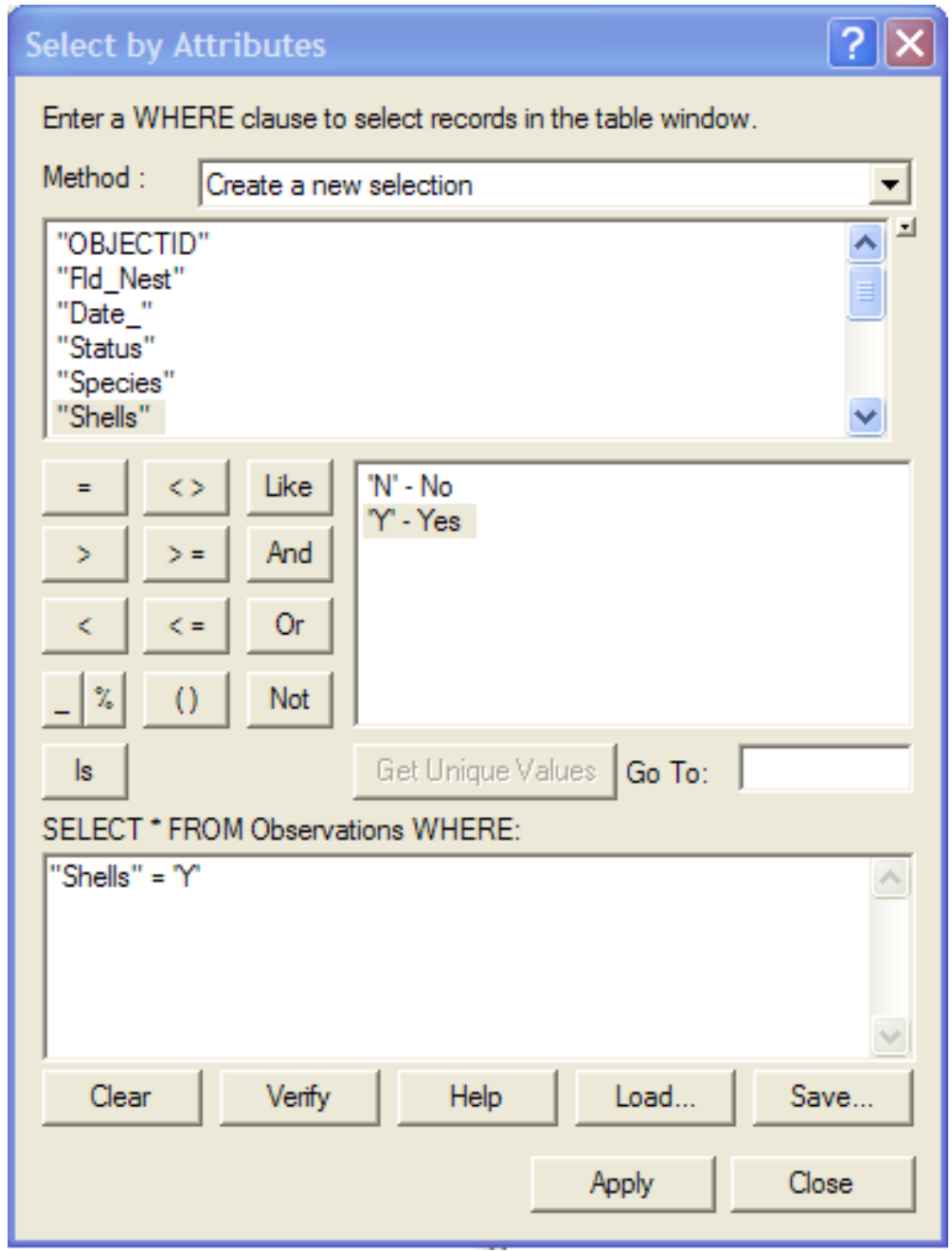

When the query box looks like this, click Apply. This will select all records identifying tortoise shells present at the site. If you want to save the query, click Save. Browse to a folder to save the query. To run the same query again, click Load, then browse to the folder in which the query was saved.

Step 8: To select records with specific number of shells, open the Select by Attributes in the Sites feature class table. Double-click the "NUM_SHELLS" field. For a specific number, click the $=$ button on the query box, and then click Get Unique Values, doubleclick the number and, or type the number leaving a space between the $=$ button. Click Apply. To see selected features on map, click Options in the Observation table. Then select Related Tables and click SiteObservations: Site Has Observations, then click Selected in the Sites attribute table.

To select records with a range of shells, you can query with $\langle$ or $>$. The example below is a query for observations with a number of shells greater than or equal to 10 . 
First, you need to clear the previous selection. Click Options in the Observations table and select Clear Selected Features. Click Options in the Sites Attribute table, and choose Clear Selected Features (or press the Clear Selection button, which will clear the selections in both tables). Click the Clear button on the SQL box.
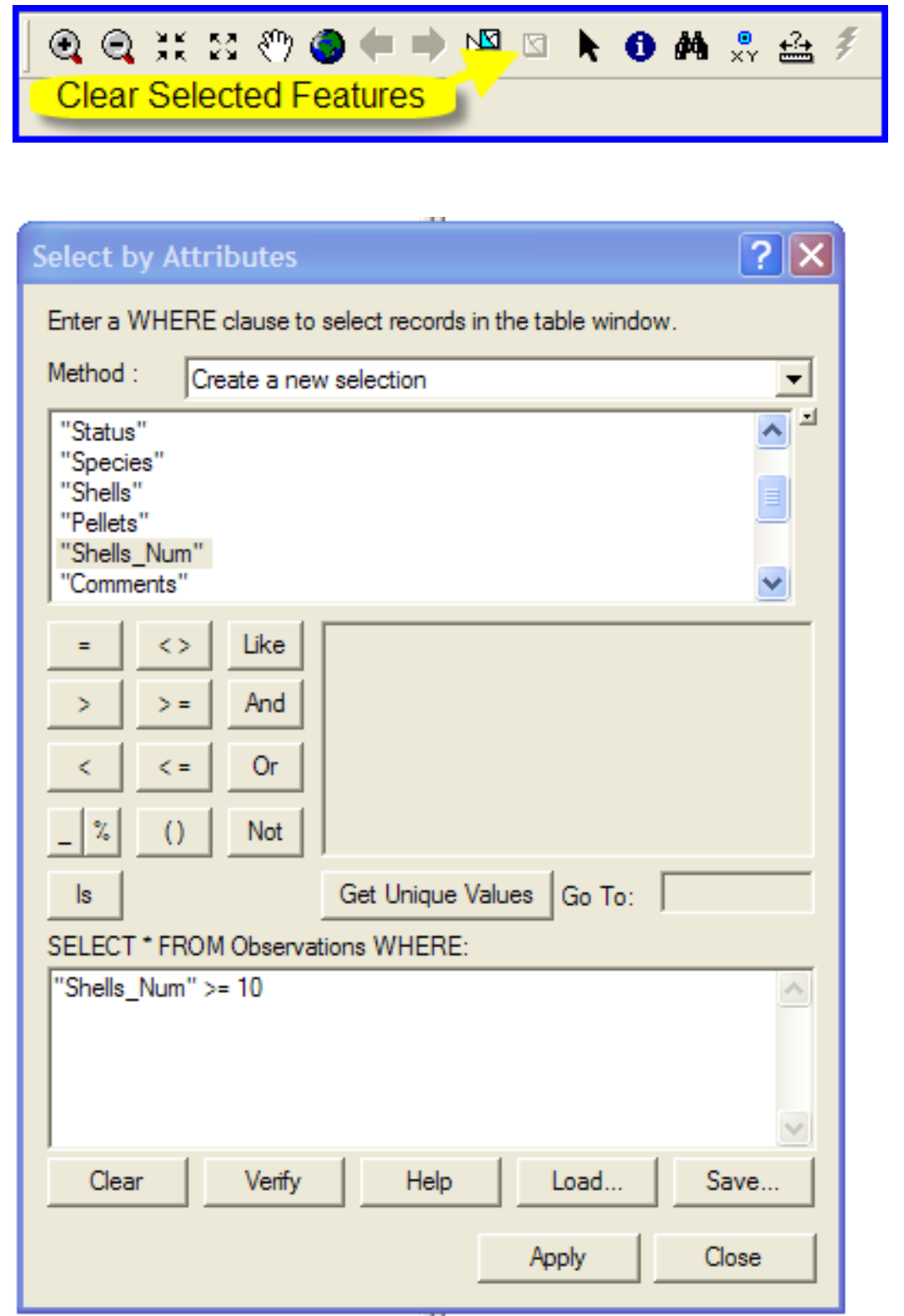

The number of selected records is at the bottom of the Observations table. For this selection, there are 3 selected records out of 1859 records. To see the selected Sites, click Selected. 


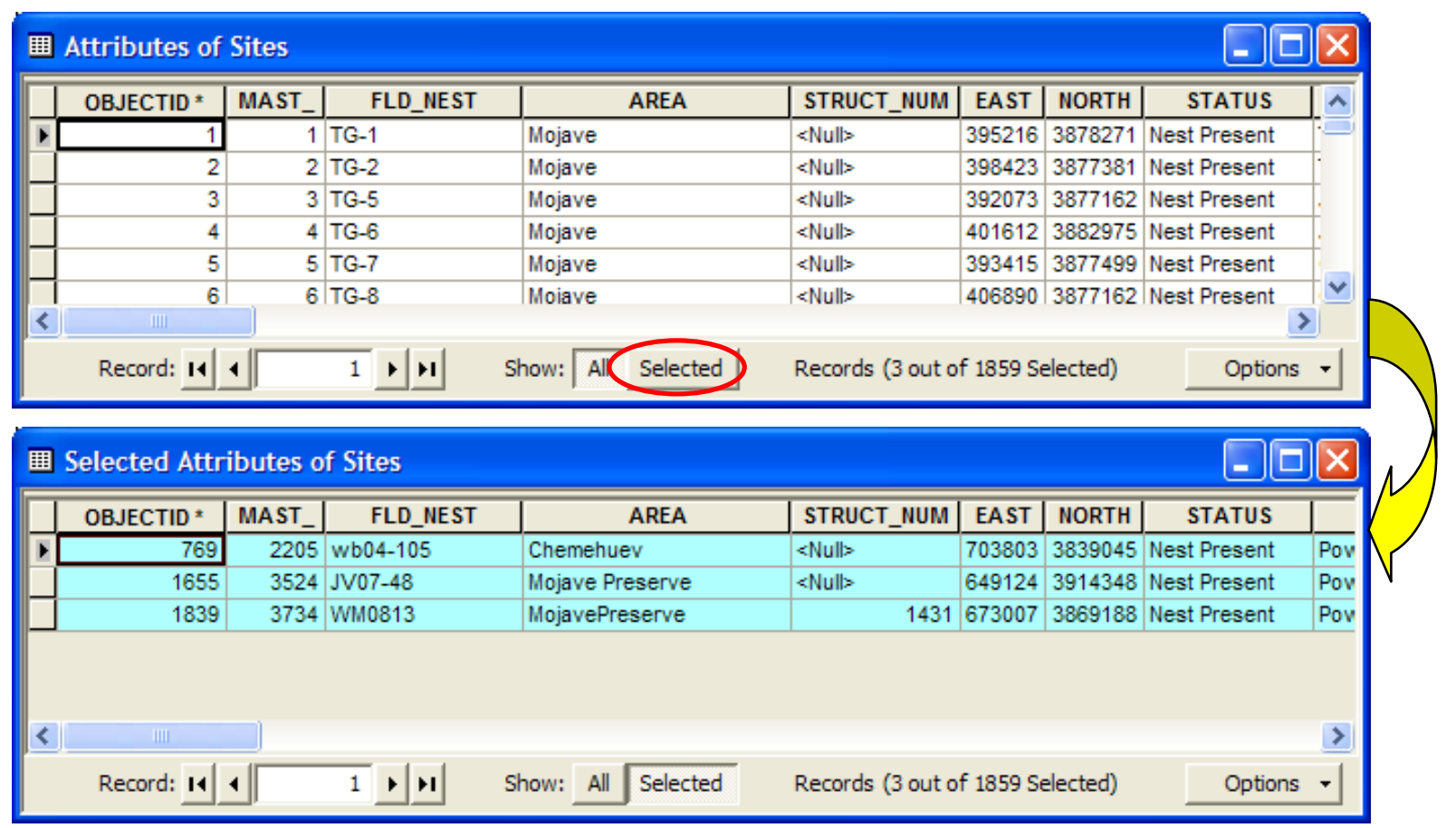

To create a new feature class with the selected Sites, right-click Sites in the table of contents, and select Data, then click Export Data. This will bring up the Export Data menu.

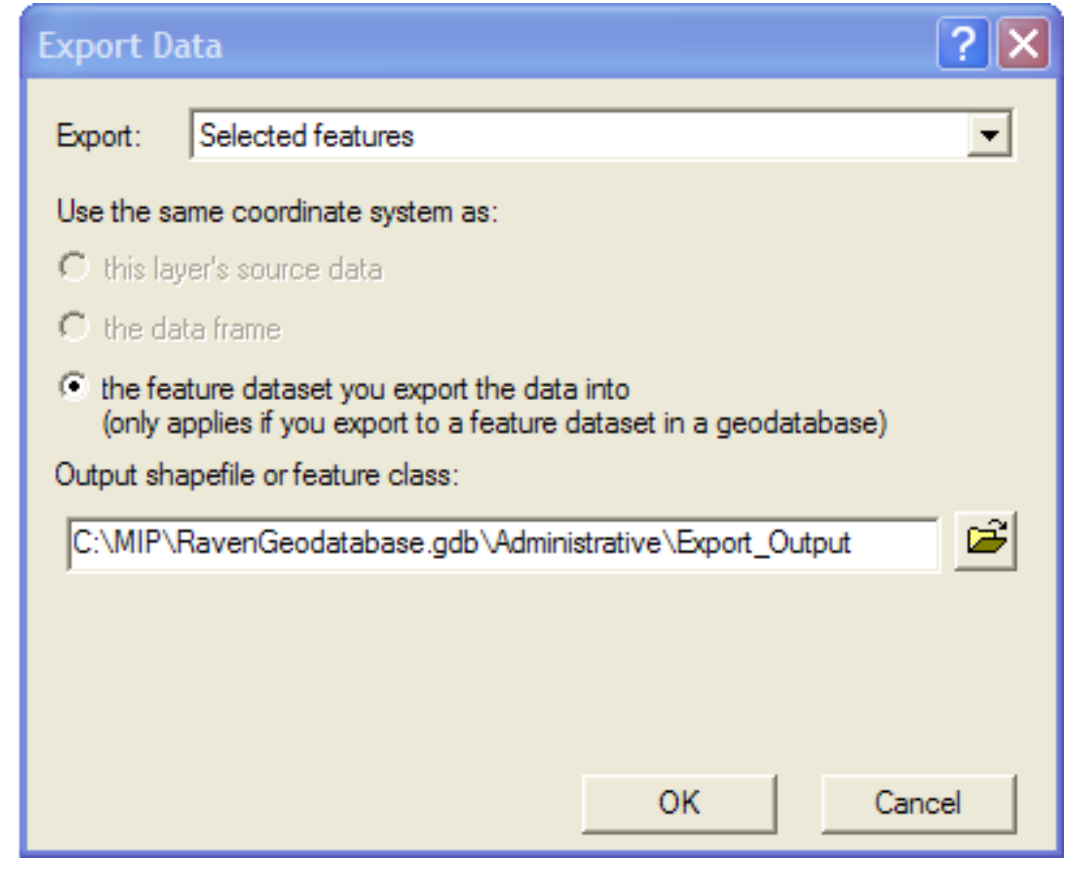

Browse to a desired location within the geodatabase to save the feature. Be sure to give it a unique name to indicate what the feature contains. For this demonstration, do not save the exported feature. 
Step 9: You must be in an Edit session to add a record. First you need to clear the previous selection (leave Observations table open). At the top of the page, click Selection and choose Clear Selected Features. Alternatively, you can click the Clear Selected Features button on the Standard Menu.

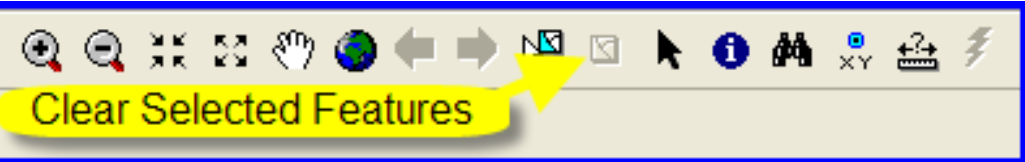

On the Editor toolbar, select Edit. This will open a drop-down menu. Select Start Editing. The grayed-out areas should appear white and look like the image below. If Sites is not in the Target menu, then click the down arrow and select Sites.

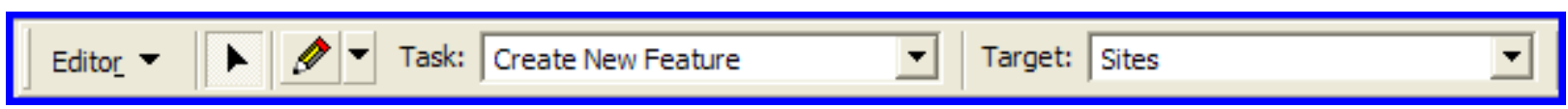

Select the Sketch tool.

Editor - $\quad$ Sketch Tool $\rightleftharpoons$

Hover the mouse pointer over the data view and right-click, and select Absolute X, Y. Insert the UTM coordinates of the nest location. For example, input 489649, 3858362.

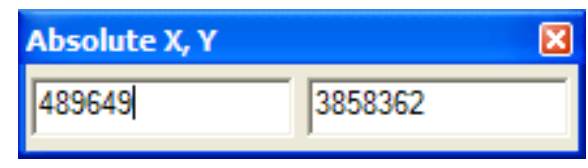

Press the Enter Key. This will place the new point according to the input coordinates. Then right-click Sites and open the Attributes table. Scroll to the last record. 


\begin{tabular}{|c|c|c|c|c|c|}
\hline \multicolumn{6}{|c|}{ 围 Attributes of Observations } \\
\hline & OBJECTID * & Fld_Nest & Date__ & Status & \\
\hline & 1744 & JV07-84 & $5 / 16 / 2007$ & Nest Present & UI \\
\hline & 1745 & JV07-83 & $5 / 16 / 2007$ & Nest Present & UI \\
\hline & 1746 & JV07-81 & $5 / 16 / 2007$ & Nest Present & UI \\
\hline & 1747 & J107-31 & $5 / 16 / 2007$ & Nest Present & CH \\
\hline & 1748 & J107-33 & $5 / 16 / 2007$ & Nest Present & UI \\
\hline & 1749 & $\mathrm{~J} 107-38$ & $5 / 16 / 2007$ & Nest Present & UI \\
\hline & 1750 & J107-37 & $5 / 16 / 2007$ & Nest Present & $\mathrm{CH}$ \\
\hline & 1751 & JV07-82 & $5 / 16 / 2007$ & Nest Present & UI \\
\hline & 1752 & JV07-80 & $5 / 16 / 2007$ & Nest Present & $\mathrm{CH}$ \\
\hline & 1753 & $J 107-36$ & $5 / 16 / 2007$ & Nest Present & $\mathrm{CP}$ \\
\hline & 1754 & $\mathrm{~J} 107-32$ & $5 / 16 / 2007$ & Nest Present & $\mathrm{CH}$ \\
\hline & 1755 & J107-35 & $5 / 16 / 2007$ & Nest Present & $\mathrm{CH}$ \\
\hline & 1756 & $J 107-34$ & $5 / 16 / 2007$ & Nest Present & $\mathrm{CH}$ \\
\hline & 1757 & & $5 / 16 / 2007$ & Nest Present & $\mathrm{CH}$ \\
\hline & 1758 & & $5 / 16 / 2007$ & Nest Present & UI \\
\hline \multicolumn{6}{|l|}{-} \\
\hline \multirow[t]{2}{*}{$\leq$} & & & IIIII & & \\
\hline & Record: $\mathbf{1 4}$ & 1 & Show: & Selected & \\
\hline
\end{tabular}

The last record should be the point you added with Absolute X, Y.

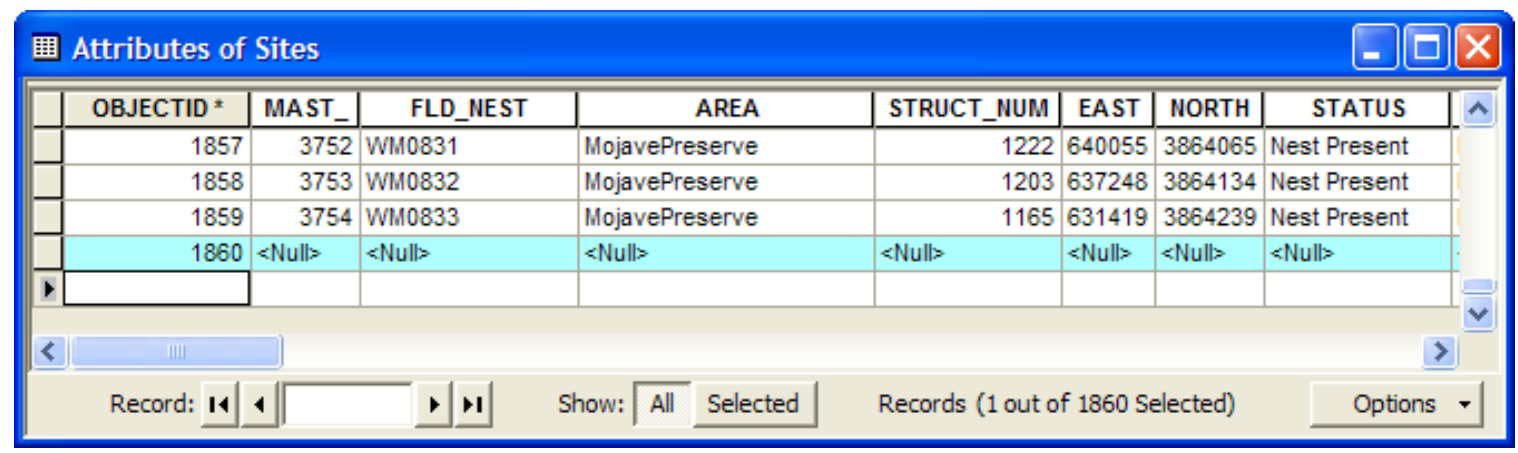

Now you can fill in the rest of the attributes for this new location. You will have to create a new MasterID unless you want an observation from a previous location. If the site already has a MasterID number, then input that number. After you have input data into this field, the OBJECTID field automatically fills in. You will also have to input the FLD_NEST, AREA, STRUCT, NUM, EAST, and NORTH coordinates. This will be how you input data from records from the field into Sites feature class. The Substrate, Status, Shells, and Pellets fields have domains, therefore; you have to select data from the drop-down menu. 


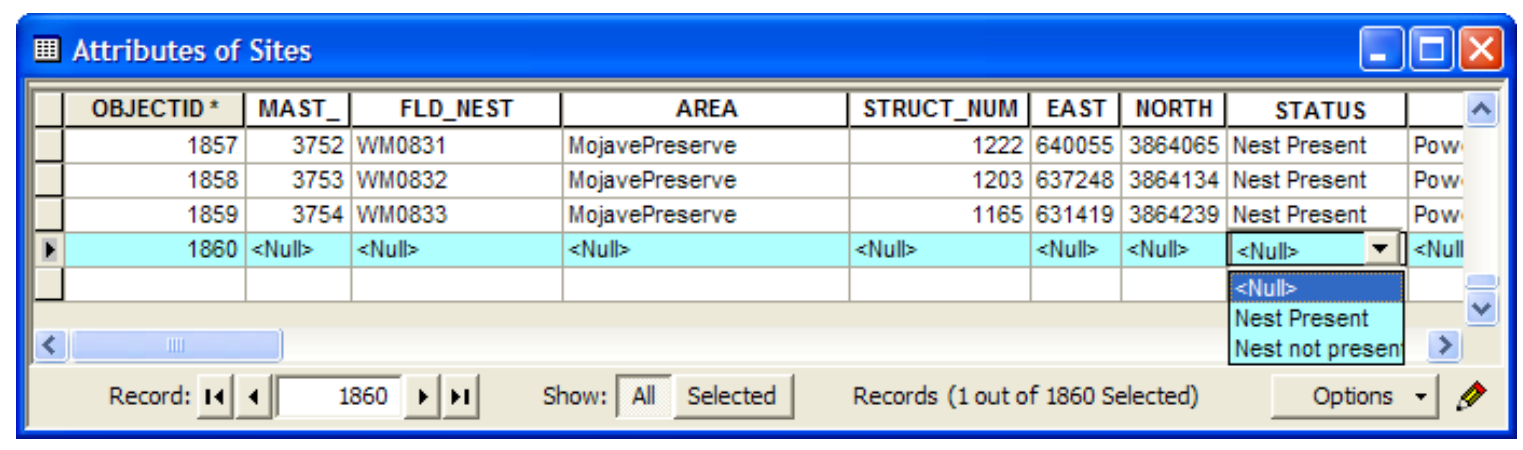

Save your edits often. (For this demonstration, do not save edits.) To do this, select Edit from the Editor Toolbar, then select Save Edits. When you are done with editing, select Edit from the Editor toolbar and select Stop Edits. If you have not saved edits before selecting Stop Edits, a pop-up menu will ask if you want to save your edits. Click No since for this demonstration. You would click Yes if you wanted to keep the edits.

Close all tables that are open in ArcMap.

Step 10: This section queries attributes in the Sites feature class. Right-click Sites, click Options, then click Select by Attributes. Scroll to "DATE_" and double-click "DATE_" field. This selects the "Date_" field for the query. Then select the > symbol. For records from the year 2004, follow the image below. 


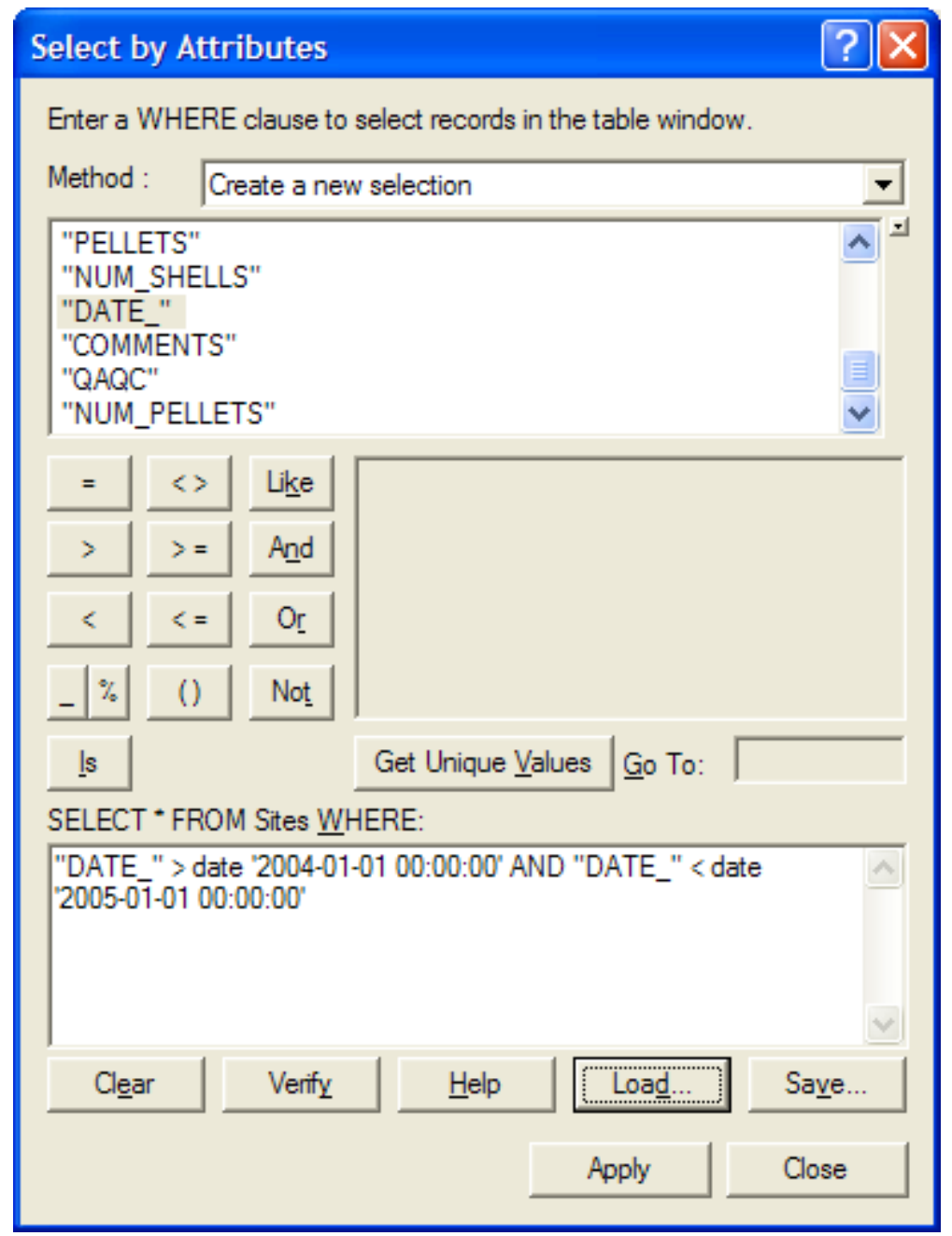

The "DATE_" field has time incorporated with it. To select a year, you have to input the date as the first day of the year at midnight, and then input the first day at midnight for the following year. This will select all the records within the year specified.

NOTE: Queries have already been created for each of the years and are located in the Queries folder named for each specific year. To retrieve the queries, click Load and browse to the Queries folder and the select year you want.

R:IProjects\DTP\Projects\RavenResearch \RavenDatabaselQueries)

Click Verify to make sure the SQL query is correct. A pop-up window will appear stating whether the query has been verified or not. If it is successful, then click OK.

Next click Apply, right-click Sites in the table of contents and select Selection. Then select Create layer from Selected Features. This creates a new layer in the map (but does not create a layer in the geodatabase).

Double-click Sites Selection (this will be the new feature added to the map), then select the General tab. For Layer Name, type "2004 Sites".

Step 11: To change the query and layer to the year 2005, follow step 10 but change the query for the year 2005. A query has already been saved. Click Load in the Select by 
Attributes menu and browse to 2005 found in the Queries folder under RavenDatabase. Other queries are available as well. Press the Clear Selection button.

Step 12: This section will show you how to symbolize the points. Right-click Sites and select Properties. Select the Symbology tab, then select the point feature.

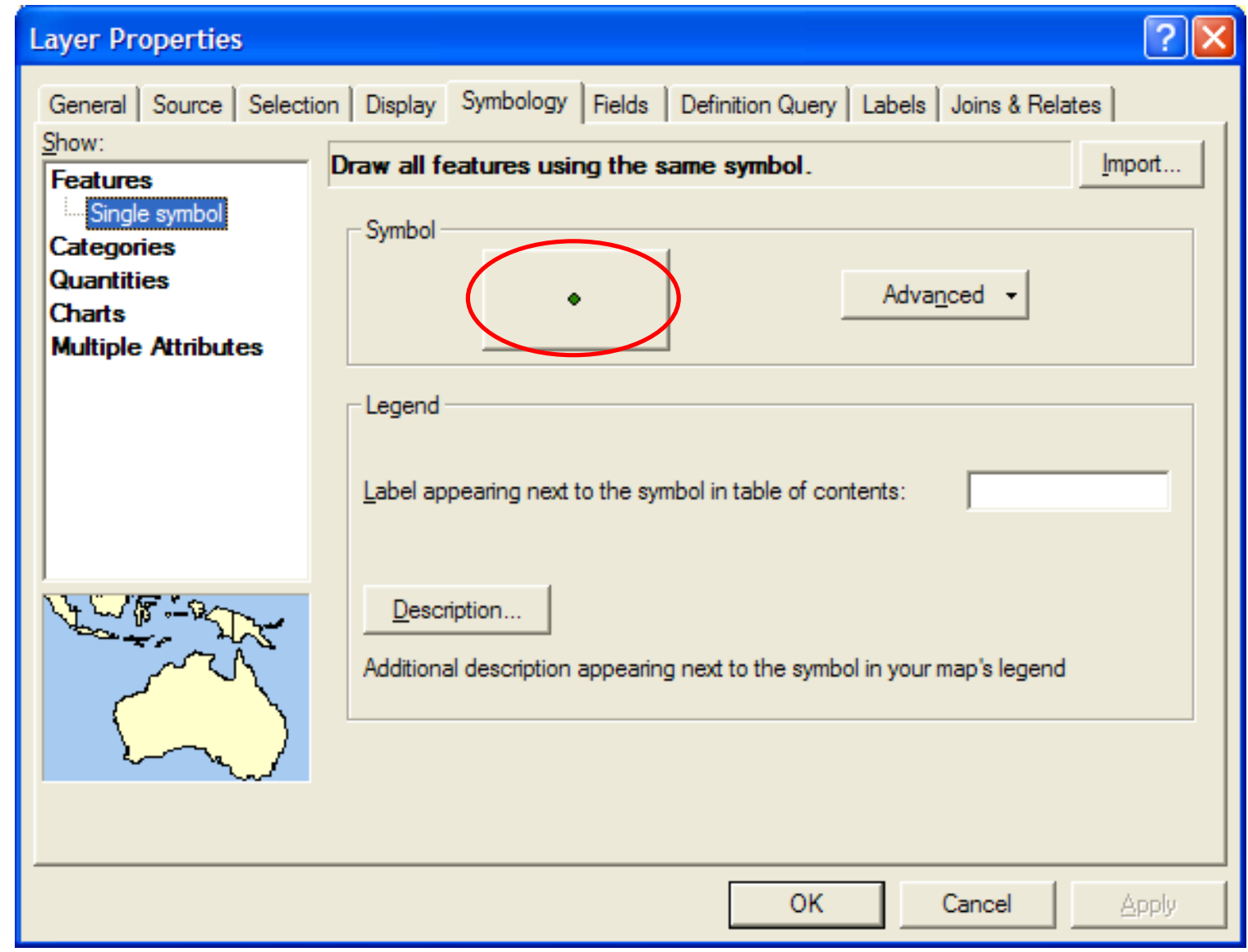

This will open the Symbol Selector window. 


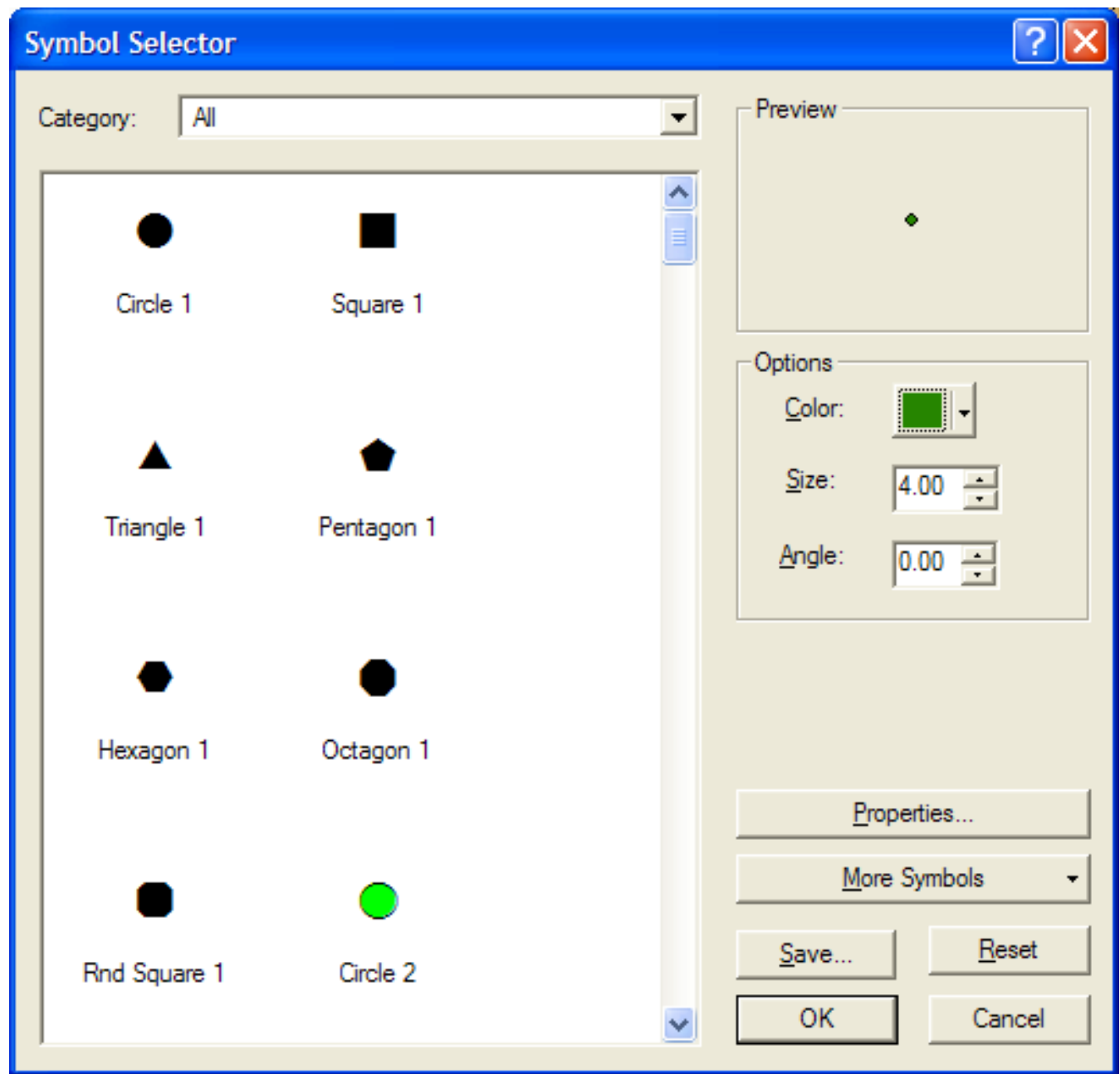

You can choose type of symbol, color, and size you want to use.

Close ArcMap. It is not necessary to save your map. 

Appendix B - Data Sources 


\section{Appendix B - Data Sources}

The data is referenced based on the location in the geodatabase.

\begin{tabular}{|c|c|c|}
\hline DATA & SOURCE & WEBSITE \\
\hline Administrative & Feature Dataset & \\
\hline $\begin{array}{l}\text { Common Raven } \\
\text { Habitat }\end{array}$ & $\begin{array}{l}\text { California Department of Fish and } \\
\text { Game's California Wildlife Habitat } \\
\text { Relationship System }\end{array}$ & \\
\hline Continents & ESRI & \\
\hline $\begin{array}{l}\text { Desert Tortoise } \\
\text { Habitat }\end{array}$ & $\begin{array}{l}\text { California Department of Fish and } \\
\text { Game's California Wildlife Habitat } \\
\text { Relationship System }\end{array}$ & \\
\hline Landfills & $\begin{array}{l}\text {-County of Kern Engineering Survey } \\
\text { Services Department } \\
\text {-County of San Bernardino Solid } \\
\text { Waste Management Division } \\
\text {-Los Angeles County Department of } \\
\text { Regional Planning } \\
\text {-Riverside County Waste } \\
\text { Management Department }\end{array}$ & \\
\hline Major Cities & ESRI & \\
\hline Military Lands & U.S. Bureau of Land Management & \\
\hline Mojave Desert & Mojave Desert Ecosystem Program & $\begin{array}{l}\text { http://www.mojavedata.gov/datasets. } \\
\text { php?\&qclass=bnd }\end{array}$ \\
\hline $\begin{array}{l}\text { National Parks } \\
\text { (southern } \\
\text { California) }\end{array}$ & National Park Service & $\begin{array}{l}\text { http://science.nature.nps.gov/nrdata/ } \\
\text { quickoutput2.cfm?UnitSearch=\& } \\
\text { Action=\&nps_quicksearch=\%2B }\end{array}$ \\
\hline Power Lines & U.S. Geological Survey Sagemap & http://sagemap.wr.usgs.gov \\
\hline $\begin{array}{l}\text { Tortoise } \\
\text { Critical Habitat } \\
\text { Units }\end{array}$ & U.S. Fish and Wildlife Service & \\
\hline U.S. Counties & ESRI & \\
\hline U.S. States & ESRI & \\
\hline Urban Areas & U.S. Census Bureau & \\
\hline Hydro & Feature Dataset & \\
\hline Lakes & USGS & \\
\hline Reservoirs & USGS & \\
\hline Rivers & USGS & \\
\hline Biological & Feature Dataset & \\
\hline Sites & $\begin{array}{l}\text { Wendy McIntyre, Ph.D., Professor of } \\
\text { Environmental Studies at the } \\
\text { University of Redlands }\end{array}$ & \\
\hline
\end{tabular}




\begin{tabular}{|l|l|l|}
\hline Transportation & Feature Dataset & \\
\hline Highways & ESRI & \\
\hline DEM & -USGS Center for Earth Resource & \\
& Observation and Science (EROS) & \\
& -National Aeronautics and Space & \\
& Administration (NASA) & \\
& -National Geospatial-Intelligence & \\
& Agency (NGA) & \\
& -Environmental Systems Research & \\
& Institute (ESRI) & \\
\hline Hillshade & & \\
\hline
\end{tabular}

